\title{
Kidins220/ARMS mediates the integration of the neurotrophin and VEGF pathways in the vascular and nervous systems
}

\author{
F Cesca ${ }^{*, 1,9}$, A Yabe ${ }^{2,9}$, B Spencer-Dene ${ }^{3}$, J Scholz-Starke ${ }^{1}$, L Medrihan $^{1}$, CH Maden ${ }^{4}$, H Gerhardt $^{5}$, IR Orriss ${ }^{6}$, P Baldelli $^{1}$, M Al-Qatari ${ }^{7}$, \\ $M_{\text {Koltzenburg }}{ }^{7}$ RH Adams ${ }^{8}$, F Benfenati ${ }^{1,10}$ and G Schiavo ${ }^{2,10}$
}

Signaling downstream of receptor tyrosine kinases controls cell differentiation and survival. How signals from different receptors are integrated is, however, still poorly understood. In this work, we have identified Kidins220 (Kinase $D$ interacting substrate of $220 \mathrm{kDa}$ )/ARMS (Ankyrin repeat-rich membrane spanning) as a main player in the modulation of neurotrophin and vascular endothelial growth factor (VEGF) signaling in vivo, and a primary determinant for neuronal and cardiovascular development. Kidins220 ${ }^{-l-}$ embryos die at late stages of gestation, and show extensive cell death in the central and peripheral nervous systems. Primary neurons from Kidins220 ${ }^{-l-}$ mice exhibit reduced responsiveness to brain-derived neurotrophic factor, in terms of activation of mitogen-activated protein kinase signaling, neurite outgrowth and potentiation of excitatory postsynaptic currents. In addition, mice lacking Kidins220 display striking cardiovascular abnormalities, possibly due to impaired VEGF signaling. In support of this hypothesis, we demonstrate that Kidins220 constitutively interacts with VEGFR2. These findings, together with the data presented in the accompanying paper, indicate that Kidins220 mediates the integration of several growth factor receptor pathways during development, and mediates the activation of distinct downstream cascades according to the location and timing of stimulation.

Cell Death and Differentiation (2012) 19, 194-208; doi:10.1038/cdd.2011.141; published online 3 November 2011

Companion paper of: doi:10.1038/cddis.2011.108

In the central (CNS) and peripheral (PNS) nervous systems, neurons rely on several trophic pathways, such as neurotrophin (NT) signaling via tropomyosin-related kinase (Trk) receptors, ${ }^{1}$ and glial cell-derived neurotrophic factor signaling via the Ret tyrosine kinase/glial cell-derived neurotrophic factor family receptor $\alpha,{ }^{2}$ to regulate axonal growth, dendritic branching, synapse assembly and plasticity. ${ }^{1,3}$ The noncatalytic p75 NT receptor (p75 NTR) functions in complex with Trks to induce survival responses. In addition, $\mathrm{p} 75^{\mathrm{NTR}}$ in association with sortilin binds pro-NTs, such as pro-nerve growth factor (NGF), to trigger apoptotic pathways. ${ }^{3}$

Several mutant mouse lines lacking NT receptors or their ligands have been generated. NT impairment in vivo often results in perinatal lethality, reflecting the prominent role played by these factors in development. ${ }^{4}$ Some of these mutant mice display CNS defects. In particular, TrkB-deficient animals show a reduction in lumbar motor neurons (MNs) ${ }^{5}$ as well as increased perinatal cell death in several brain regions. ${ }^{6}$ However, the CNS is largely unaffected by the deletion of single NTs or Trk receptors, suggesting that during development different growth factors compensate for each other. ${ }^{4,7}$ In the PNS, neuronal loss is seen in specific ganglia, such as the vestibular and cochlear $\left(\mathrm{BDNF}^{-1-}, \mathrm{NT}^{-1-}\right.$, $\mathrm{TrkB}^{-1-}$ and $\mathrm{TrkC}^{-l-}$ ), ${ }^{8,9}$ or sympathetic superior cervical ganglia $\left(\mathrm{NGF}^{-l-11}\right)$, as well as in dorsal root ganglia (DRGs), where specific neuronal pools are lost in mice lacking distinct NTs or their receptors. ${ }^{7}$ Non-neuronal phenotypes have also been observed. For example, both NT3 ${ }^{-1-}$ and $\mathrm{TrkC}^{-1-}$ mice display cardiac phenotypes such as septal and valve malformations, whereas $\mathrm{BDNF}^{-/-}$and $\mathrm{TrkB}^{-/-}$mice display ventricular wall hemorrhages and abnormal vasculature. In addition, mice lacking $\mathrm{p} 75^{\mathrm{NTR}}$ display perinatal lethality due to the rupture of blood vessels. ${ }^{11}$

${ }^{1}$ Department of Neuroscience and Brain Technologies, The Italian Institute of Technology, via Morego 30, 16163 Genoa, Italy; ${ }^{2}$ Molecular Neuropathology Laboratory, Cancer Research UK London Research Institute, 44 Lincoln's Inn Fields, London WC2A 3LY, UK; ${ }^{3}$ Experimental Pathology Laboratory, Cancer Research UK London Research Institute, 44 Lincoln's Inn Fields, London WC2A 3LY, UK; ${ }^{4}$ Institute of Ophthalmology, University College London, Bath Street, London EC1V 9EL, UK; ${ }^{5}$ Vascular Biology Laboratory, Cancer Research UK London Research Institute, 44 Lincoln's Inn Fields, London WC2A 3LY, UK; ${ }^{6}$ Department of Cell and Developmental Biology, University College of London, Gower Street, London WC1E 6BT, UK; ${ }^{7}$ Institute of Child Health, University College of London, 30 Guildford Street, London WC1N 1EH, UK and ${ }^{8}$ Max Planck Institute for Molecular Biomedicine, Roentgenstrasse 20, 48149 Muenster, Germany

*Corresponding author: F Cesca, Department of Neuroscience and Brain Technologies, The Italian Institute of Technology, via Morego 30, 16163 Genova, Italy.

Tel: + 3901071781788; Fax: + 3901071781230; E-mail: fabrizia.cesca@iit.it

${ }^{9}$ These authors contributed equally to this work.

${ }^{10}$ These authors contributed equally to this work.

Keywords: Kidins220/ARMS; Neurotrophin signaling; Synaptic plasticity; VEGF receptor

Abbreviations: BDNF, brain-derived neurotrophic factor; CNS, central nervous system; DIV, days in vitro; DRG, dorsal root ganglia; EPSC, excitatory postsynaptic current; ES, embryonic stem; Kidins220/ARMS, kinase D interacting substrate of $220 \mathrm{kDa} /$ ankyrin repeat-rich membrane spanning; MAPK/Erk, mitogen-activated protein kinase/extracellular signal-activated kinase; MN, motor neuron; NGF, nerve growth factor; Nrp1, neuropilin-1; NT, neurotrophin; p75 ${ }^{\mathrm{NTR}}$, p75 neurotrophin receptor; PNS, peripheral nervous system; Trk, tropomyosin-related kinase receptor; VEGF, vascular endothelial growth factor; VEGFR, vascular endothelial growth factor receptor

Received 08.3.11; revised 13.9.11; accepted 20.9.11; Edited by G Melino; published online 03.11.11 
Kidins220 (Kinase $D$ interacting substrate of $220 \mathrm{kDa}$ )/ ARMS (Ankyrin repeat-rich membrane spanning), referred to hereafter as Kidins220, is a transmembrane protein containing cytoplasmic domains involved in protein-protein interactions. $^{12,13}$ Several partners for Kidins220 have been identified, including the NT receptors Trks and $\mathrm{p} 75^{\mathrm{NTR}}, 13,14$ the Rho-GEF Trio, ${ }^{15}$ NMDA and AMPA receptors. ${ }^{16,17}$ Kidins220 participates in the activation of the mitogenactivated protein kinase/extracellular signal-activated kinase (MAPK/Erk), ${ }^{14}$ Jak/Stat ${ }^{18}$ and NF- $\mathrm{B}^{19}$ pathways, downstream of NT and ephrin signaling. It modulates basal synaptic activity $^{17,20}$ and regulates neuronal polarity and dendrite specification both in vitro ${ }^{21}$ and in vivo. ${ }^{22}$ Furthermore, Kidins220 has a critical role in the control of cell survival, as it mediates the neuroprotective effect of brain-derived neurotrophic factor (BDNF) in cortical neurons. ${ }^{19}$

Here and in the accompanying paper, ${ }^{23}$ we defined a major in vivo function of Kidins220 in the development of the nervous and cardiovascular systems. Using Kidins220 knockout mice, we found that Kidins220 has a crucial role in the integration of several growth factor receptor pathways in different tissues, and mediates the activation of distinct downstream signaling cascades according to the location and timing of growth factor stimulation.

\section{Results}

Generation of Kidins220 knockout mice. To delete the Kidins220 gene in mice, we inserted a Kidins220 cDNApolyA cassette flanked by two loxP sites in the unique $\mathrm{Nrul}$ site within exon 16 of the mKidins220 gene (Figure 1A). In Kidins $220^{\text {lox/lox }}$ mice, Kidins220 mRNA is transcribed under the control of its endogenous promoter, generating the fulllength protein. Upon crossing these mice with strains expressing Cre recombinase, the floxed region is removed, yielding an mRNA encoding the $\mathrm{N}$-terminal portion of Kidins220 fused to $\beta$-galactosidase (lacZ). Recombinant clones were screened for the $5^{\prime}$ and $3^{\prime}$ recombination sites (Figure 1Bb). Three clones showed the expected hybridization pattern by Southern blot, confirming that a single integration had occurred (Supplementary Figure S1).

Kidins220 $20^{\mathrm{lox} /}$ animals were generated by blastocyst injection, back-crossed to $\mathrm{C} 57 \mathrm{BI} / \mathrm{J}$ and then crossed with males expressing Cre recombinase under the ubiquitous phosphoglycerate kinase promoter, which is active from early stages of embryogenesis. ${ }^{24}$ Kidins $220^{+/-}$animals were viable and fertile, and did not show any overt behavioral phenotype. Kidins $220^{+/-}$crosses, however, yielded only
A

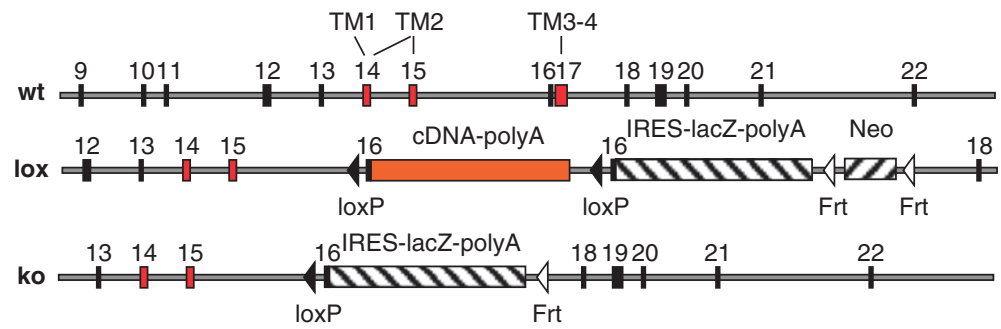

B

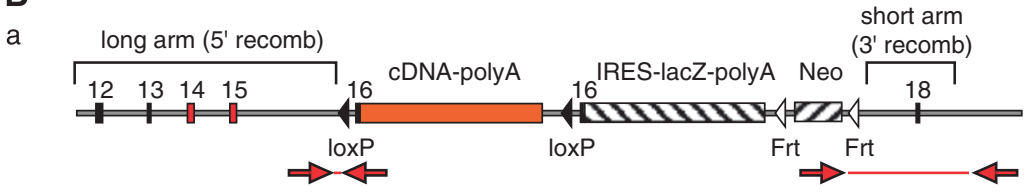

b

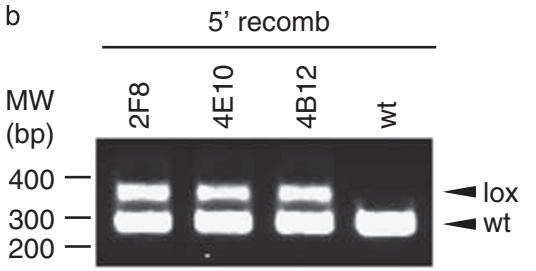

D

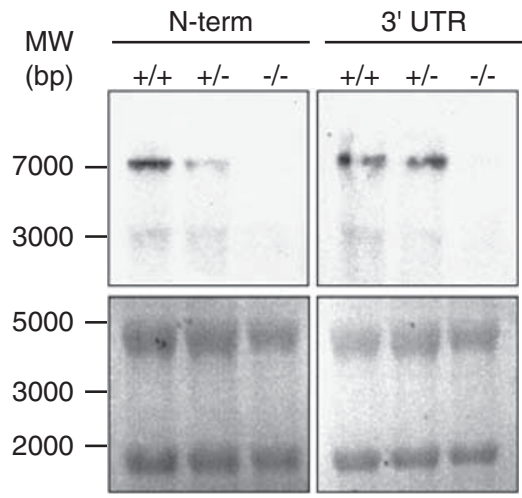

E MW

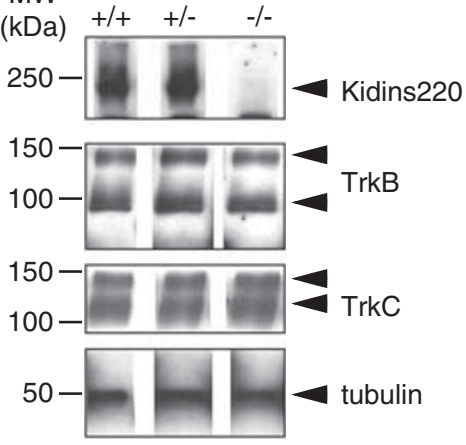

Figure 1 Generation of Kidins220 knockout mice. (A) The pFIrt construct recombined with the wild-type allele (wt; exon 9-22 of the Kidins220 gene), generating the lox allele (lox). The knockout allele (ko) is generated upon Cre excision. TM, transmembrane domain. (Ba) Probes for the PCR screen (red arrows) are indicated. (b) PCR for $5^{\prime}$ and $3^{\prime}$ recombination sites in a wild-type and three recombinant ES clones. Chimeras were derived from the 4B12 clone. (C) Kidins $220^{-1-}$ embryos develop to late stages of gestation, but are smaller than their littermates. (D) Total RNA was extracted from Kidins220 wild-type $(+I+)$, heterozygous $(+I-)$ or knockout $(-I-)$ E18.5 brains, blotted and hybridized with $3^{\prime} U T R$ and N-terminal-specific probes (upper panels). The RNA gel was imaged before blotting, showing equal amount of total RNA (lower panels). (E) Brains from E18.5 embryos were analyzed by western blotting using anti-Kidins220, anti-TrkB and anti-TrkC antibodies. Tubulin was used as loading control 
wild-type and Kidins $220^{+/-}$animals, suggesting the full Kidins220 knockout is embryonic lethal. The three genotypes were present at the expected Mendelian ratio up to E18. Kidins $220^{-/}$embryos were indistinguishable from their littermates up to E15, however, by $E 18$ they displayed overt growth defects (Figure 1C) and died before birth.

To confirm Kidins220 knockout, mRNA levels were analyzed by northern blot (Figure 1D). We could not detect any signal in Kidins $220^{-1-}$ samples, suggesting that the mRNA encoding the Kidins220-lacZ protein undergoes nonsensemediated decay. Accordingly, no $\beta$-galactosidase activity was detected in extracts from Kidins $220^{+/-}$or Kidins $220^{-1-}$ embryos (not shown). Some Kidins 220 mRNA were detected by PCR, however, this did not yield any protein. ${ }^{1}$ Western blot analysis showed complete Kidins220 loss in knockout brains (Figure 1E), ${ }^{1}$ whereas expression of other Kidins220 interactors, such as TrkB and TrkC, ${ }^{15}$ was unaffected (Figure 1E). Antibodies against the $\mathrm{N}$ - and C-terminus of Kidins $220^{16,25}$ revealed comparable levels of full-length protein in heterozygote and wild-type samples, ${ }^{1}$ explaining why Kidins $220^{+/-}$ mice are functionally indistinguishable from wild type. Thus, we focused our analysis to only wild-type and Kidins $220^{-1-}$ embryos.

E18.5 Kidins220 ${ }^{-1-}$ embryos showed striking heart abnormalities with dilated and congested atria. ${ }^{1}$ The ventricle wall was vacuolated and disorganized, suggesting that atrial dilation could be secondary to ventricle malfunctioning. ${ }^{1}$ Such a compromised heart might not be strong enough to withstand the stress of birth, and therefore cause the death of mutant animals.

Kidins220 loss affects specific neuronal pools in the CNS. Kidins220 is ubiquitously expressed in adult mouse brain (http://mouse.brain-map.org/brain/C330002l19Rik.html), spinal cord and DRGs (http://mousespinal.brain-map.org/ gene/detail/C330002l19Rik.html). We asked whether Kidins220 ablation would affect the survival of specific neuronal populations. We stained wild-type and Kidins $220^{-1-}$ brain sections at various developmental stages for active caspase 3, an apoptosis marker. No immunoreactive cells were detected up to E13.5. ${ }^{1}$ Cell death was observed from E15.5 to E16.5, when clusters of caspase 3-positive cells were evident in the ventral neuroepithelium, retina, thalamus ${ }^{1}$ and cortex (Figure 4A). This pattern became progressively more severe during development. At E18.5 mutant brains were smaller than wild type (Figure $2 A$ ), and caspase 3-positive cells were present in the ventral neuroepithelium and subventricular zone (Figure 2B), cingulum and dorsal subiculum of the hippocampus, cortex and caudate putamen (Figure 2C). At a more caudal level, we found caspase 3-positive cells in the ventroposterolateral and medial thalamic nuclei, and in the nucleus reuniens (Figures $2 \mathrm{D}$ and $4 \mathrm{C}$ ). The $3 \mathrm{D}$ reconstruction of a wild type and a Kidins $220^{-1-}$ E18.5 brain highlighted the abnormal ventricle enlargement in mutant embryos (Supplementary Movies 1 and 2).

Kidins220 in sensory and MN development. Kidins220 is expressed in DRGs and ventral horn of the spinal cord, where MNs are located. ${ }^{14}$ We therefore asked whether Kidins220 ablation affects development and/or survival of these neurons. Serial sections of spinal cords from E13.5 wild-type and Kidins $220^{-1-}$ embryos were stained for active caspase 3 (Figure 3Aa). A significant increase in the number of apoptotic cells in Kidins $220^{-1-}$ DRGs was found at both thoracic and lumbar levels (Figure 3Ab). However, cell death in DRGs did not affect specific sub-populations, but impacted equally on all the neuronal subtypes analyzed, and the ratio between different neuronal populations was unchanged. ${ }^{1}$ We conducted a similar analysis on vestibular and glossopharyngeal ganglia (Figure 3B), ${ }^{1}$ whose development depends on NT signaling, ${ }^{9}$ and found an increased number of active caspase 3-positive cells in both ganglia (Figure $3 \mathrm{Bb})$. To assess MN survival, we performed Nissl staining on lumbar (L3-L5) sections of spinal cord in E18.5 wild-type and Kidins $220^{-1-}$ littermates. MNs, recognized on the basis of their size and morphology ${ }^{26}$ (Figures $3 \mathrm{Ca}$ and b), were reduced in Kidins $220^{-1-}$ embryos compared with wild type (Figure 3Cc). Altogether, our results indicate that Kidins220 has a role in the survival of these neuronal populations.

Kidins220 in brain vascular development. Kidins $220^{-/-}$ brains appeared poorly vascularized and often hemorrhagic (not shown). Staining with isolectin B4, an endothelial marker, on E16.5 and $\mathrm{E} 18.5$ brain sections revealed abnormal vascular patterning in Kidins $220^{-1-}$ tissue, where vessels were larger in diameter (Figure $4 \mathrm{~A}$ ) and unable to make correct projections, and formed glomeruloid terminal structures in the subventricular zone (Figures $4 \mathrm{~B}$ and $\mathrm{C}$ ). This phenotype was present throughout the fore-/mid-brain, including areas adjacent to the lateral ventricle and the third ventricle, in the thalamic region. Interestingly, these regions correspond to some of the areas displaying massive apoptosis (Figures 2B and D), as confirmed by co-staining with anti-caspase 3 antibodies. These results suggest that the observed cell death could be explained, at least in part, by defective vascularization.

Figure 2 Active caspase 3-positive areas in Kidins220 ${ }^{-1-}$ E18.5 brains. Brain sections from wild-type, Kidins220 ${ }^{+/-}$and Kidins220 ${ }^{-1-}$ E18.5 embryos were stained for active caspase 3. Heterozygous samples were undistinguishable from wild type (not shown). Staining was performed on $n=3$ embryos per genotype from at least two different litters. (A) Upper panel: the Kidins220 ${ }^{-1-}$ brain (KO) appears grossly normal, albeit slightly smaller than the wild type. Lower panel: dashed lines indicate the planes of sections for the images shown in B-D. (B) Active caspase 3-positive cells in the neuroepithelium and subventricular zone (c and d, arrowheads, compare with wild type in a, b). (C) Active caspase 3-positive cells in the cortex (e and f, arrowheads, compare with a and b), dorsal subiculum of the hippocampus (e and g, two arrowheads, compare with a and $\mathrm{c}$ ), and in parts of the caudate putamen (e and $\mathrm{h}$, arrowhead, compare with a and d). (D) Active caspase 3-positive cells in the ventral posteromedial and medial thalamic nuclei (e and $f$, arrowheads, compare with $a$ and $b$ ), as well as in the nucleus reuniens of the thalamus ( $g$ and $h$, arrowheads, compare to $c$ and $d)$. Scale bars in $\mathbf{A}, \mathbf{B}$ (a, $c$ ), C $(a, e), \mathbf{D}(a, c, e, g)=1 \mathrm{~mm}$; in B (b, d), C (b, d, f, h), D (b, d, f, h) =200 $\mu \mathrm{m}$. 3v, 3rd ventricle; cpu, caudate putamen (striatum); ctx, cortex; dg, dentate gyrus; ds, dorsal subiculum; Iv, lateral ventricle; $\mathrm{ml}$, medial lemniscus; ne, neuroepithelium; ov, olfactory ventricle (olfactory part of lateral ventricle); re, reuniens thalamic nucleus; vpl, ventral posterolateral thalamic nucleus; vpm, ventral posteromedial thalamic nucleus 
Since such a phenotype presents with similarities to that observed in neuropilin 1 (Nrp1) knockout embryos, ${ }^{27}$ we asked whether Kidins220 interacts with the Nrp1-vascular endothelial growth factor receptor (VEGFR) complex. To this end, we used an immortalized brain endothelioma cell line
(bEND5), in which Kidins220, Nrp1, VEGFR2, the major VEGF receptor isoform, ${ }^{28}$ and VEGFR3, are constitutively expressed (Figure 4D). Cells were kept in full medium, serumstarved overnight, or treated for $30 \mathrm{~min}$ with recombinant VEGF-A $A_{165}$. Kidins220 was associated with VEGFR2 under
A
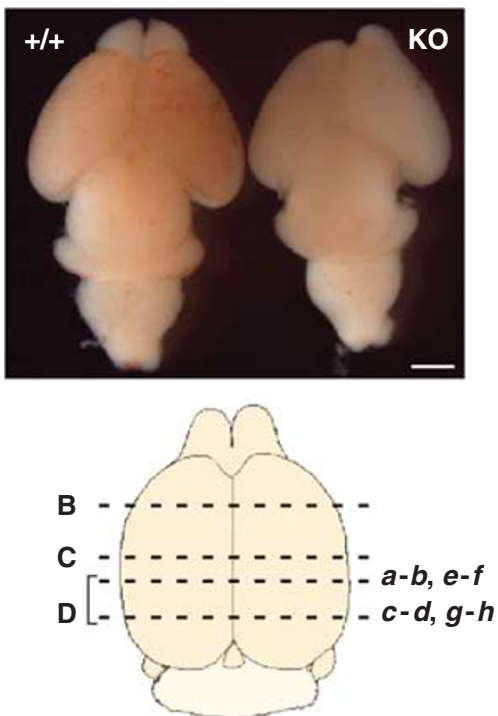

C

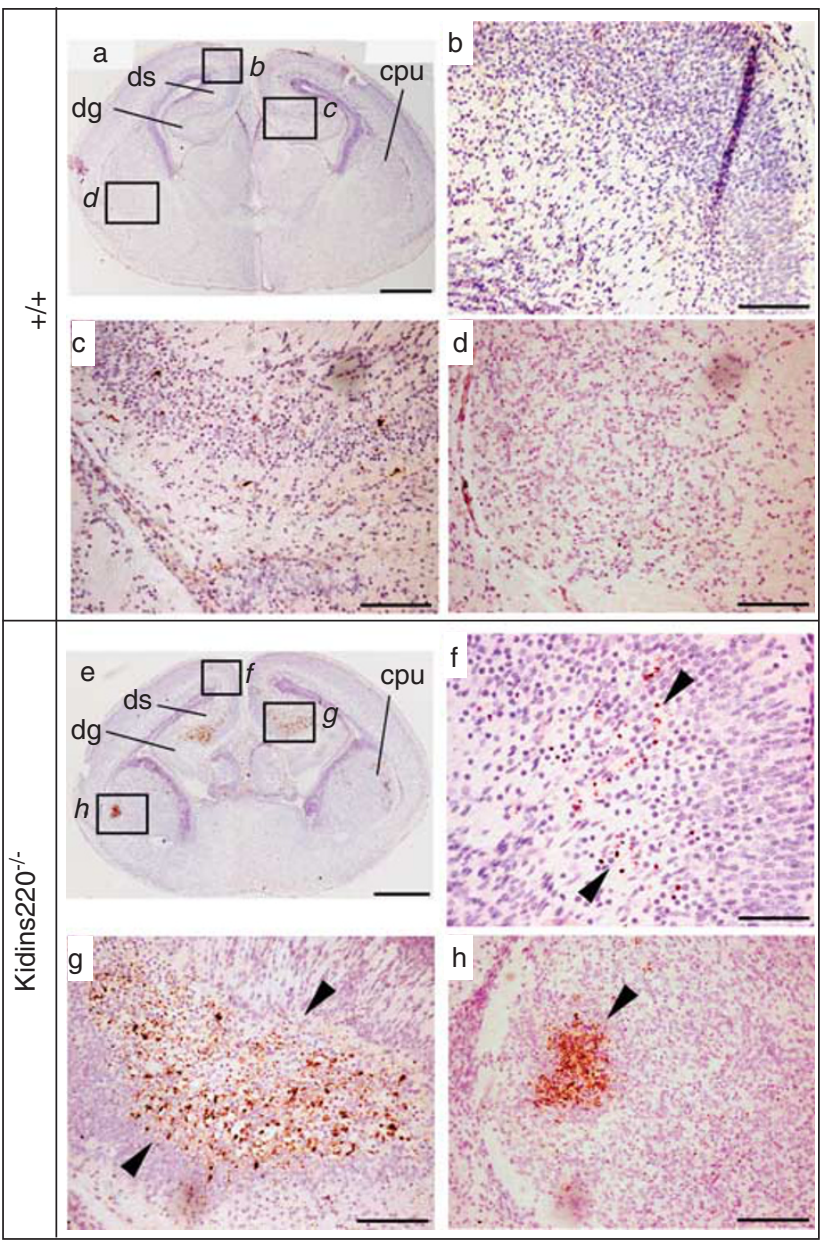

B

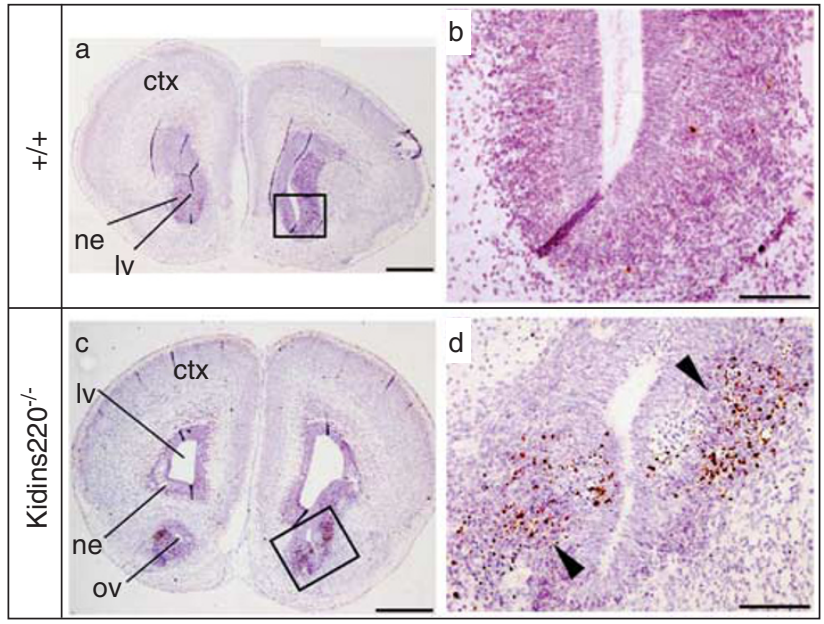

D

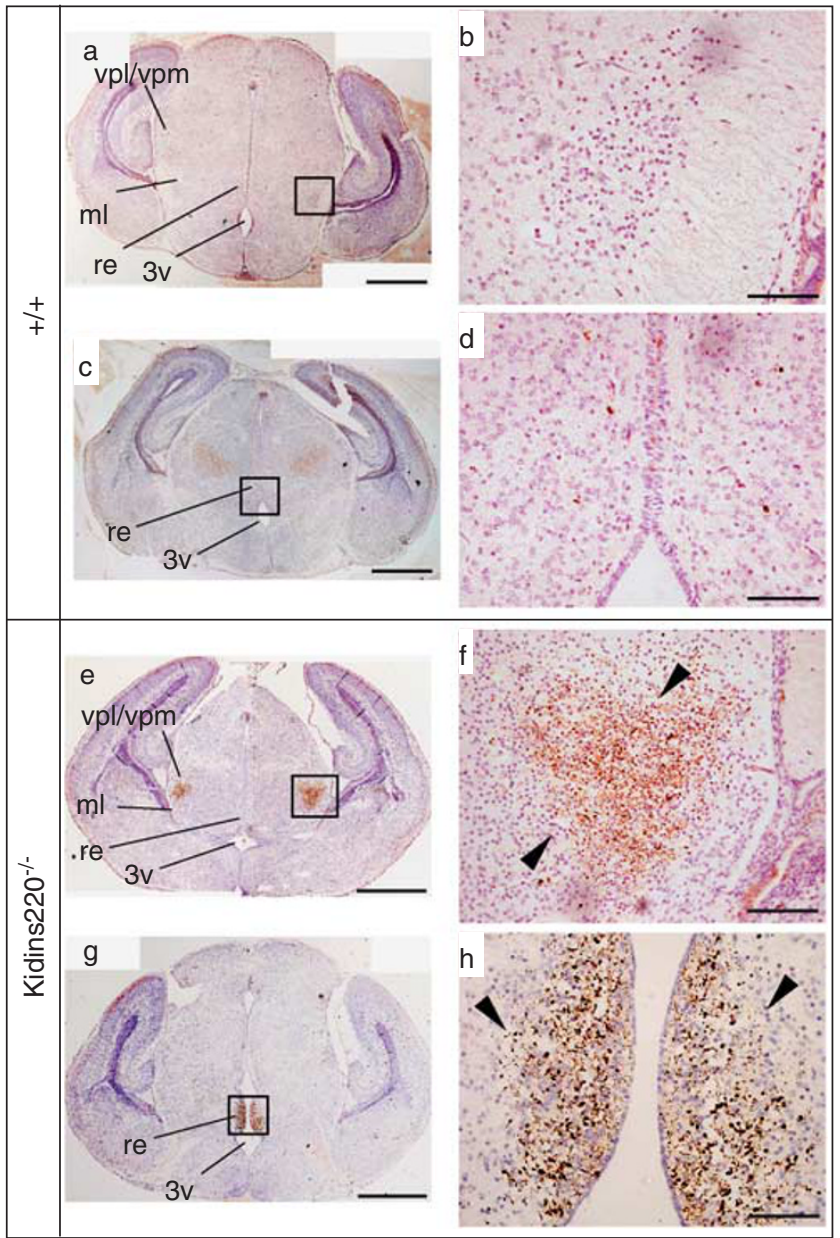


A a

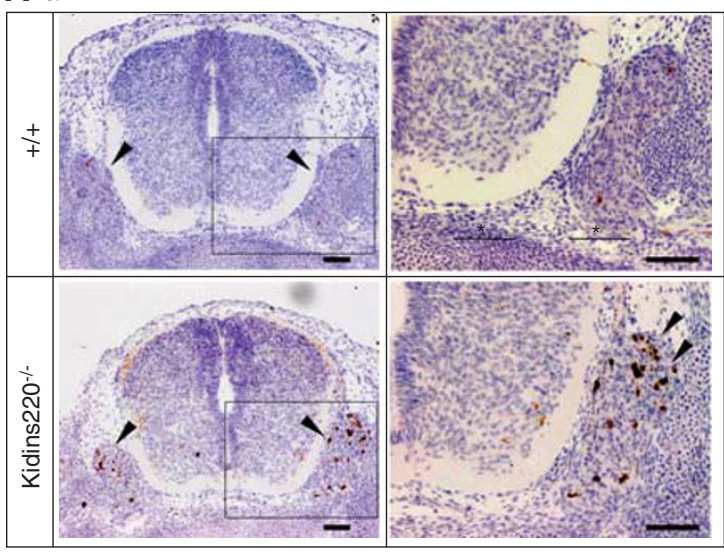

B a

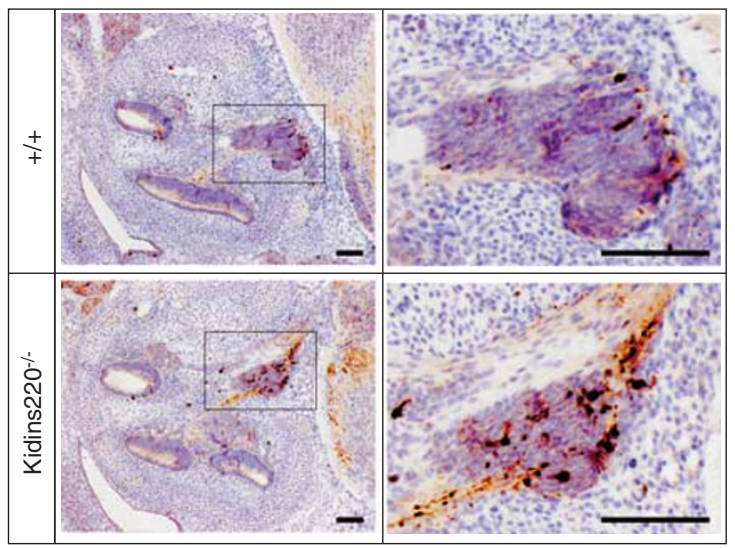

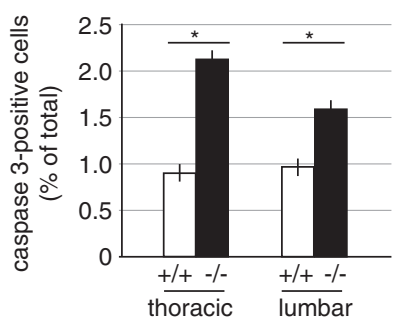

b
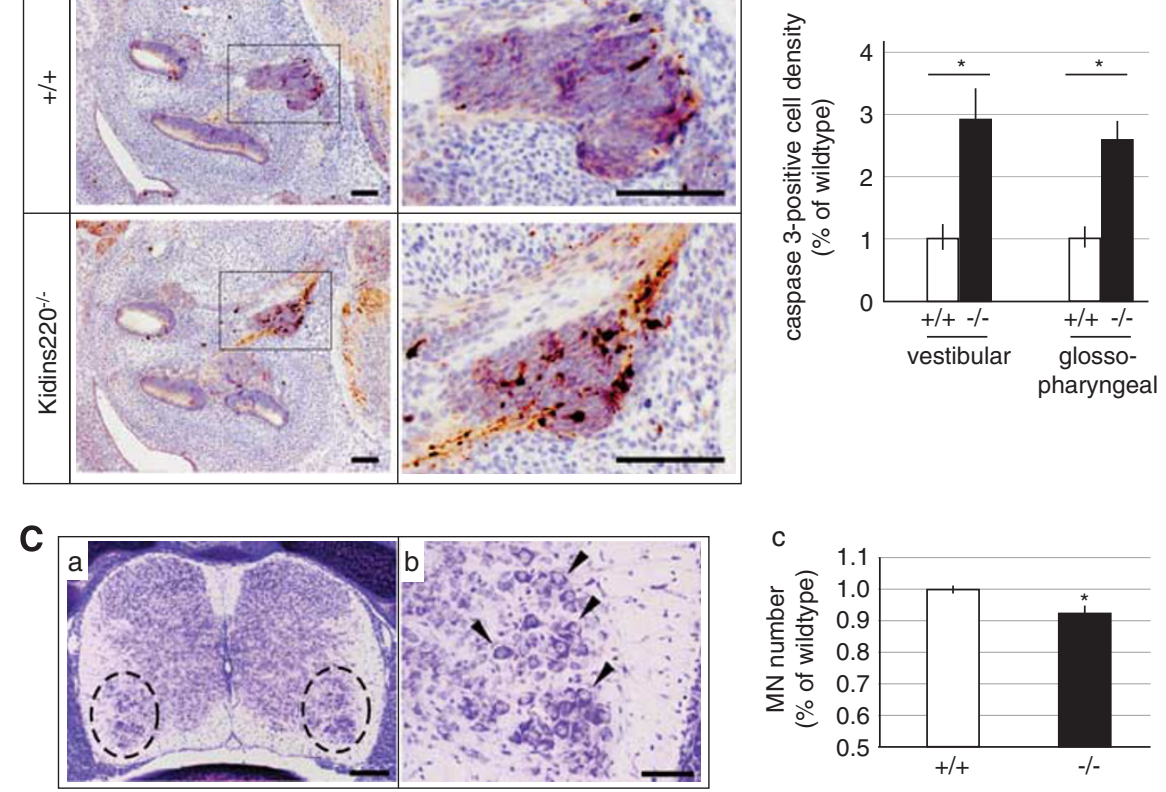

Figure 3 Differential involvement of Kidins220 in sensory and motor neuron development. (Aa) Active caspase 3 staining of DRG sections from wild-type and Kidins220 ${ }^{-1-}$ E13.5 embryo. (b) The number of immunoreactive cells was quantified in sections from thoracic and lumbar ganglia. In both cases, a significant increase in the percentage of active caspase 3-positive cells was observed in the mutant tissue, compared with the wild type ( ${ }^{\star} P<0.05$, Student's unpaired $t$-test). Data are expressed as means \pm S.E.M. (17 sections/embryo, $n=3$ wild-type and $n=4$ Kidins222 ${ }^{-1-}$ embryos). Scale bars, $100 \mu \mathrm{m}$. (Ba) Active caspase 3 staining of vestibular ganglia sections from wild-type and Kidins220 ${ }^{-1-}$ E14.5 embryos. (b) The number of immunoreactive cells was quantified in vestibular and glossopharyngeal ganglia sections, and expressed as density of active caspase 3-positive cells. A significant increase in cell death was observed in both Kidins220 ${ }^{-l-}$ ganglia ( $\left.{ }^{*} P<0.05\right)$. Data are expressed as means \pm S.E.M. (10-20 sections/ embryo, $n=3$ embryos for each genotype), setting wild-type values to 1 . Scale bars, $100 \mu \mathrm{m}$. (C) Motor neurons (MNs) were counted in lumbar (L3-L6) sections of spinal cords from wild-type and Kidins220 $0^{-1-}$ E18.5 embryos. (a) Representative section where MN pools are highlighted (black ovals), and higher magnification of the MNs in the ventral horn (b, arrowheads). (c) MNs are reduced in Kidins $220^{-1-}$ embryos compared with wild type $\left.{ }^{\star} P<0.05\right)$. Data were normalized to the number of MNs in wild-type samples and expressed as means \pm S.E.M. (30 sections/embryo; $n=3$ embryos of each genotype). Scale bars, $100 \mu \mathrm{m}$ (a), $50 \mu \mathrm{m}$ (b)

Figure 4 Kidins220 is required for capillary plexus development in the brain. Coronal sections of wild-type and Kidins220 ${ }^{-1-}$ E16.5 (A and B) or E18.5 (C) brains were stained with isolectin B4 (an endothelial cell marker, green) and for active caspase 3 (red). (A) Cortical vasculature development appears largely normal; however, cortical vessels are larger in diameter, and a distinct layer of active caspase 3-positive cells is visible in knockout samples (d, arrowheads). Blind-ended glomeruloid tufts form in the SVZ of Kidins220 ${ }^{-1-}$ lateral ventricles (Bd, arrows) and reuniens nuclei of the thalamus surrounding the third ventricle ( $\mathbf{C d}$, arrows), where clusters of active caspase 3-positive cells are observed (Bd and $\mathbf{C d}$, arrowheads). Such structures are never observed in wild-type brains (see $\mathbf{A a}, \mathrm{b}, \mathbf{B a}, \mathrm{b}$ and $\mathbf{C a}, \mathrm{b}$ ). Scale bars, $1 \mathrm{~mm}$ in panels a and c, $100 \mu \mathrm{m}$ in A, B (b, d), $200 \mu \mathrm{m}$ in C (b, d). (D-F) Kidins220 associates with VEGFR2 and VEGFR3 in bEND5 cells. (D) Cells were cultured in full serum, serum-starved or treated with recombinant VEGF-A165. VEGFR2, VEGFR3, Kidins220, Nrp1 are expressed in bEND5 cells. Phosphorylation of VEGFR2 is observed upon VEGF165 treatment, indicating activation of the receptor. (E) Kidins220 co-immunoprecipitates with VEGFR2 under all conditions tested. Purified non-immune rabbit lgG was used as negative control. (F) A specific interaction is also detected between Kidins220 and VEGFR3. VEGFR1 and Nrp1 pull-down did not yield consistent results, due to lack of antibodies immunoprecipitating efficiently the endogenous proteins. HA antibodies were used as negative control. R2, VEGFR2; R3, VEGFR3 
A

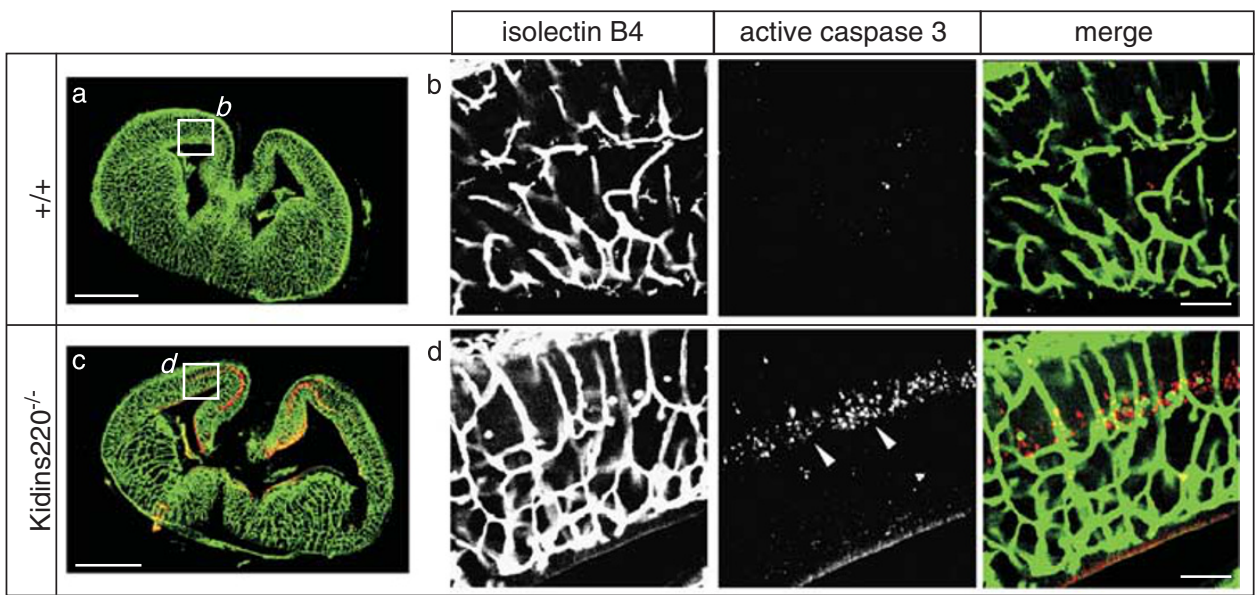

B

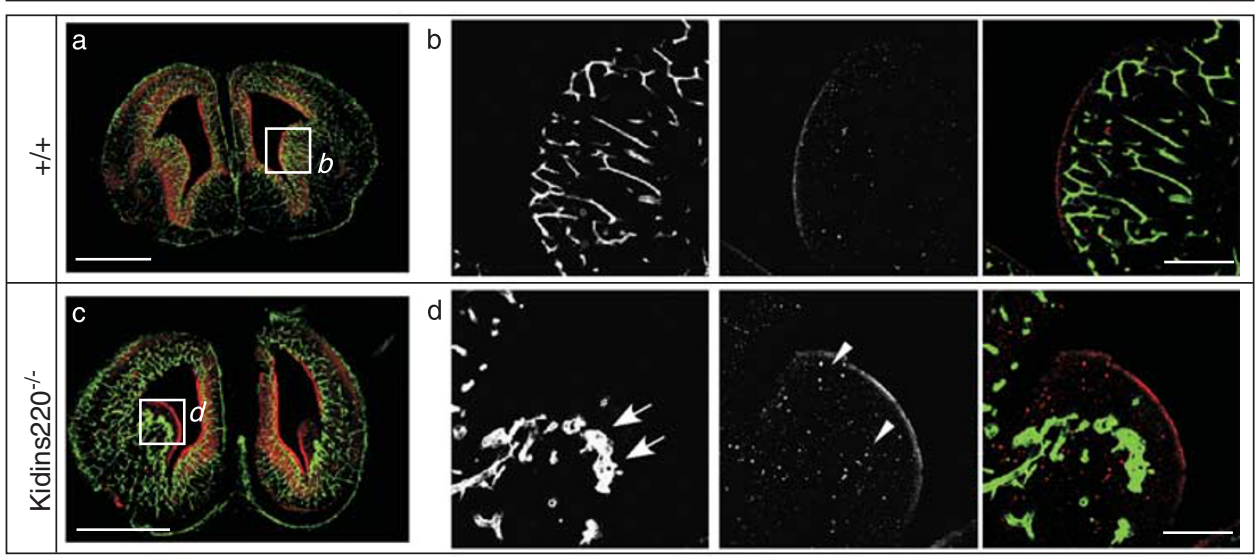

C

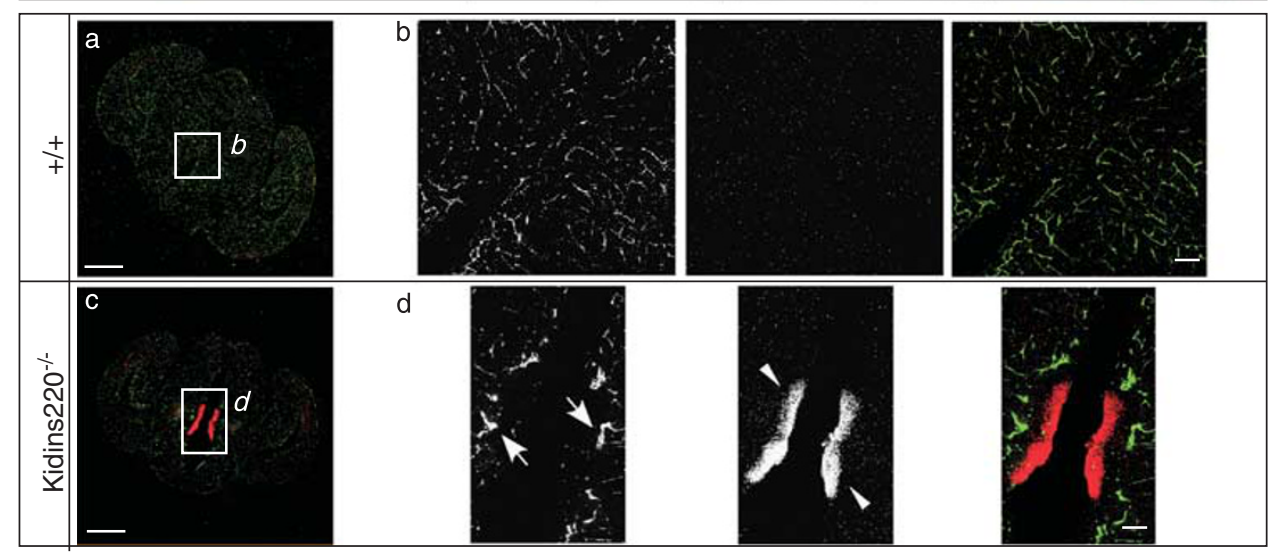

D
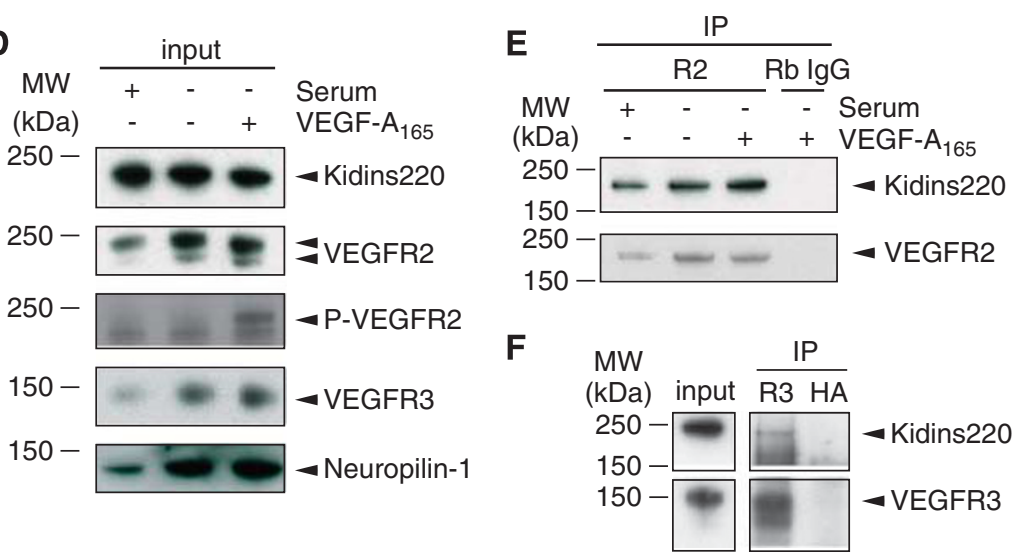
all conditions, indicating a constitutive interaction with this receptor (Figure 4E). A weaker interaction was detected with VEGFR3 (Figure 4F).

Kidins220 does not modulate proliferation in the CNS. Defective cell proliferation could contribute to the reduced brain mass of Kidins $220^{-1-}$ embryos. To address this point, we stained E13-E14 brain sections for Ki-67, a general proliferation marker, or for the phosphorylated form of histone 3 (phospho H3), a more selective mitotic marker (Figure 5). Analysis of wild-type and Kidins $220^{-1-}$ embryo sections did not reveal any major difference in the pattern of Ki-67-positive cells, in both the forebrain (Figures $5 \mathrm{~A}, \mathrm{~B}$ and $\mathrm{E}$ ) and hindbrain (Figures $5 \mathrm{~A}, \mathrm{C}$ and $\mathrm{F}$ ). Phospho H3 marks mitotic cells lining the ventricles (Figure $5 B$ ). In the ganglionic eminence, mitotic cell distribution appeared largely normal, despite the severe vascular defects affecting this region in knockout embryos (Figures $5 \mathrm{Bb}$ and e). In contrast, we noticed several misplaced mitotic cells in the cortex of mutant embryos, which were not observed in wild type (Figures 5Bc and $\mathrm{f}$, arrowheads). Altogether, these observations suggest that Kidins 220 does not regulate basal levels of proliferation, but might control progenitor migration to the appropriate cortical layer.

Altered BDNF response in Kidins $220^{-I}$ neurons. As Kidins220 acts downstream of Trk receptors, ${ }^{15}$ we asked whether Kidins220 ablation affects the ability of neurons to respond in vitro to BDNF in terms of (i) axonal and dendritic outgrowth, (ii) activation of TrkB-mediated signaling and (iii) short-term synaptic plasticity.

Young hippocampal neurons (days in vitro 2, DIV2) were kept for 2 days in basal growth medium containing BDNF (50 ng/ml; Figure 6Aa), whereas older cultures (DIV14) were cultured without addition of exogenous NTs, to assess their ability to extend their neurite network in response to endogenous stimuli (Figure 6Ab). Kidins $220^{-1-}$ neurons displayed an impaired growth factor response at both stages, resulting in a simplified neurite network. To further analyze this phenotype, neurons were treated with BDNF $(50 \mathrm{ng} / \mathrm{ml})$ for 3 days, and stained for axonal (SMI-31) or cytoskeletal ( $\beta$-III tubulin) markers. Axonal and dendritic length and branching were quantified (Figures $6 \mathrm{Ba}-\mathrm{c}$ ). Under basal conditions, Kidins $220^{-1-}$ neurons showed increased axonal length and branching compared with wild-type cells (Figure $6 \mathrm{Bb})$, whereas dendrite number, length and branching were comparable (Figure 6Bc). Upon BDNF treatment, Kidins $220^{-1-}$ neurons showed a normal axonal growth, with only minor differences on the total axonal length (Figure 6Bb), whereas they displayed overt defects in the dendritic network in terms of number, length and branching (Figure 6Bc).

To ascertain whether this growth phenotype could be explained by an alteration of the signaling pathways downstream of TrkB, we acutely treated cortical neurons (DIV14) isolated from wild-type and Kidins $220^{-1-}$ littermates with BDNF $(50 \mathrm{ng} / \mathrm{ml})$ for $40 \mathrm{~min}$, with or without pre-treatment with the Trk-specific inhibitor K252a. Kidins $220^{-1-}$ neurons showed a general impairment in the activation of signaling downstream of BDNF (Figure 7A). A statistically significant reduction in the phosphorylation of TrkB at $Y 516$ and of Erk1/2 was observed upon BDNF stimulation, whereas Akt phosphorylation was only slightly reduced. The BDNF-induced activation of these pathways was blocked by K252a, confirming the specificity of this effect. We also detected a reduction in PLC $\gamma$ activation, which, however, did not reach statistical significance $(P=0.079)$.

We monitored the total level of BDNF-induced TrkB phosphorylation by immunoprecipitation with anti-phosphotyrosine antibodies. Receptor phosphorylation in knockout samples was slightly reduced, but overall comparable to wild type (Figure 7B). This was expected, and most likely reflects the selective reduction in Y516 phosphorylation, while the phosphorylation at Y816, and presumably at other phospho-sites on the receptor, was unaffected (see above). Reduced TrkB phosphorylation may result from an impaired targeting of the receptor to the plasma membrane. To address this point, we performed membrane biotinylation experiments, which revealed a comparable amount of both full-length and truncated TrkB in knockout and wild-type samples (Figure 7C). Altogether, these results indicate that Kidins220 ablation does not impair TrkB transport or membrane insertion, but rather affects a step downstream of NT binding, which controls receptor activation and signaling.

As Kidins220 interacts with all Trk receptors, ${ }^{15}$ we asked whether it mediates signaling downstream of TrkA or TrkC. To this end, we treated wild-type and Kidins $220^{-1-}$ cortical neurons with NGF or NT3, and quantified the levels of phospho-Erk. We found a reduction in NT3-induced Erk activation in Kidins $220^{-1-}$ neurons, while we could not elicit an NGF response from either genotypes (Supplementary Figure $\mathrm{S} 2 \mathrm{~A})$. These results suggest that Kidins 220 has a general role in Trk receptor signaling. To further validate our findings, we measured BDNF response in cortico-hippocampal slices from E18.5 embryos (Supplementary Figure S2B). Consistent with the results obtained in primary neurons, we observed a reduction in BDNF-induced activation of the Erk pathway in knockout slices, compared with wild type.

BDNF-induced excitatory postsynaptic current (EPSC) potentiation is impaired in Kidins $220^{-1-}$ autapses. To assess the consequences of Kidins220 ablation, we studied the BDNF-induced potentiation of EPSCs in hippocampal autaptic neurons (DIV10-15). ${ }^{29}$ EPSCs were evoked by brief depolarization under whole-cell voltage clamp using a pairedpulse protocol (Figure 8). Representative traces are shown in Figure 8B. EPSCs were identified based on their deactivation kinetics and reversal potential, and confirmed by the firing properties of the respective neuron, or by AMPA receptor blockade (data not shown). In the absence of BDNF, the mean EPSC amplitude did not differ between wild-type and Kidins $220^{-1-}$ neurons (Figure $8 \mathrm{C}$ ). Furthermore, the pairedpulse ratio of EPSC amplitudes elicited by two stimuli separated by $50 \mathrm{~ms}$ showed a comparable amount of facilitation in both genotypes (Figure 8D). Thus, Kidins $220^{-/-}$autaptic neurons showed normal excitatory synaptic transmission and short-term synaptic enhancement.

BDNF application $(100 \mathrm{ng} / \mathrm{ml})$ evoked an increase of EPSC amplitude in wild-type neurons. In all, 8 out of 15 cells (53.3\%) responded with a potentiation between 25 and $85 \%$, whereas 
A

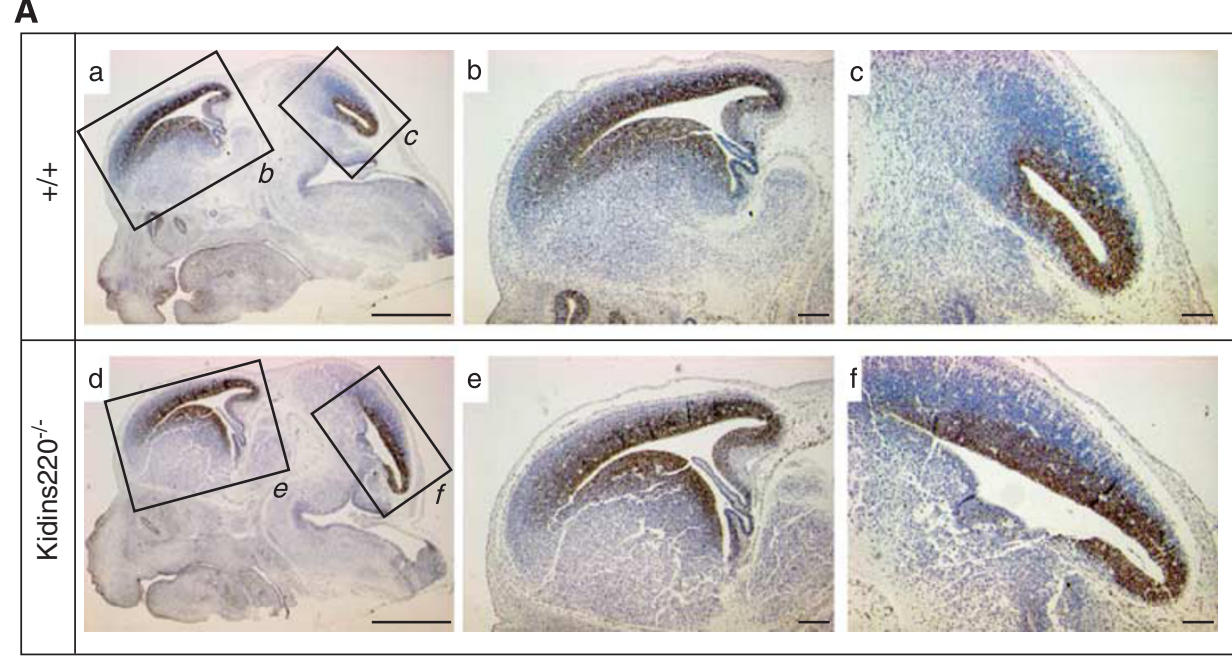

B
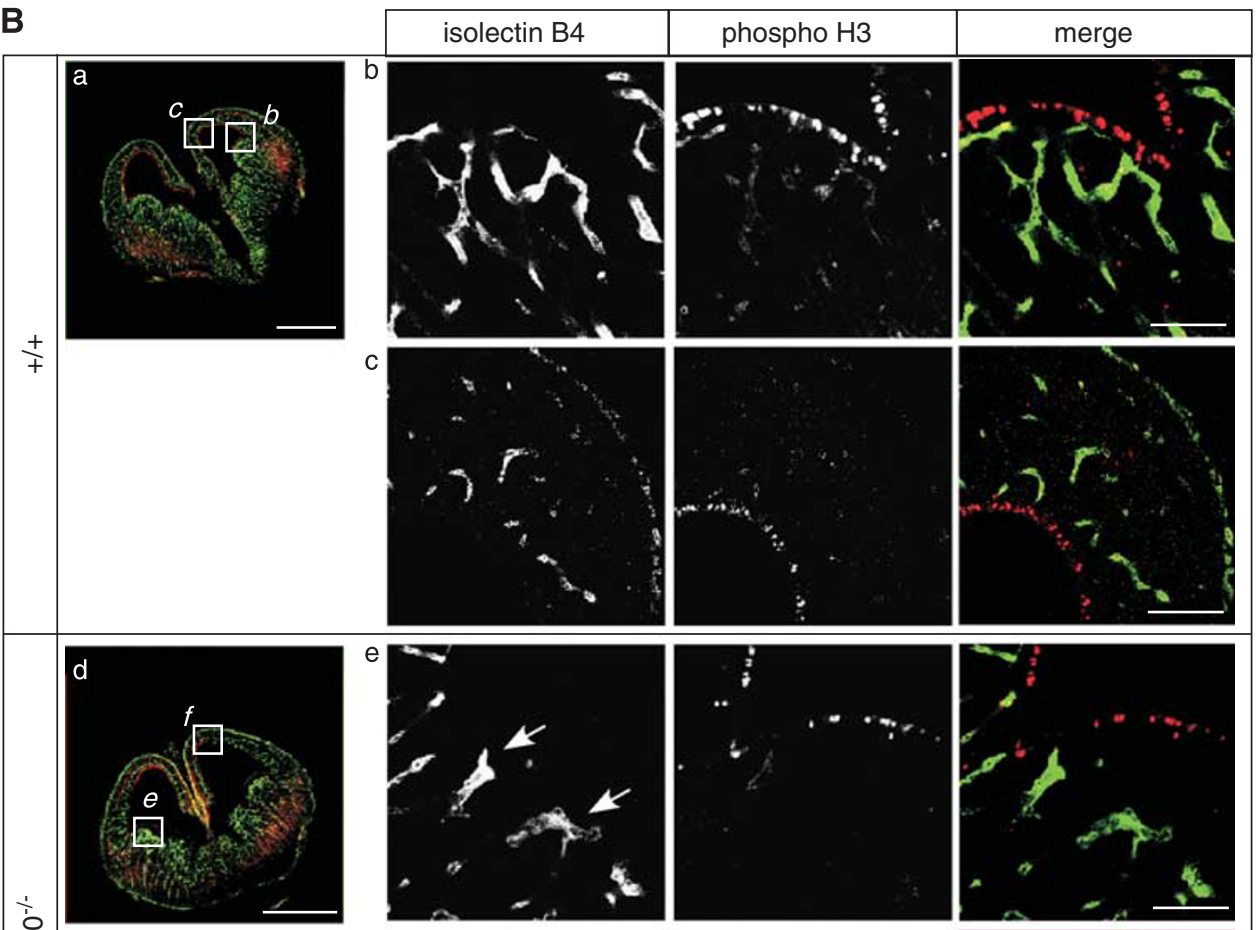

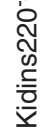
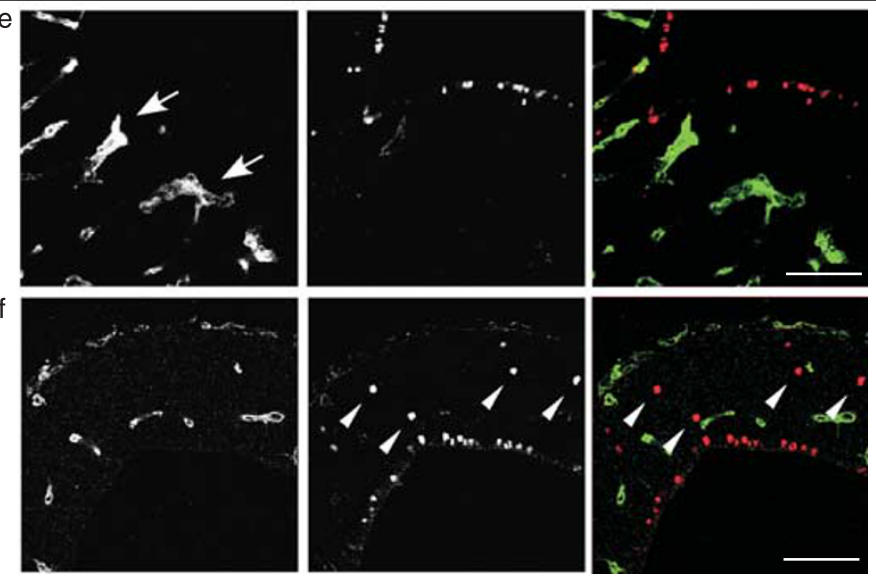

Figure 5 Kidins220 does not modulate cell proliferation in the CNS. (A) Sagittal sections of wild-type and Kidins220 ${ }^{-1}$ E13.5 brains were stained with Ki-67, a marker of cell proliferation. No macroscopic differences in cell proliferation were observed at this developmental stage, either in the forebrain (b, e) or in the hindbrain (c, $\mathrm{f}$ ). Analysis was conducted on serial sections of $n=3$ embryos per genotype, derived from two independent litters. Scale bars, $1 \mathrm{~mm}$ in a and d, $200 \mu \mathrm{m}$ in b, c, e and f. (B) Coronal sections of wild-type and Kidins220 ${ }^{-1}$ E14.5 brains were stained with an endothelial cell marker (isolectin B4, green) and for a marker of mitosis (phosphorylated histone $\mathrm{H} 3$, red). The number and distribution of proliferating cells in the SVZ are comparable in wild-type and Kidins $220^{-1-}$ brains (compare b and e), despite the vascular defects characterizing the knockout samples (e, arrows). In contrast, in the cortical region, where vascular development is largely normal, several misplaced proliferating cells were observed, which were absent in wild-type tissue (compare $\mathrm{c}$ and $\mathrm{f}$, arrowheads) 
A

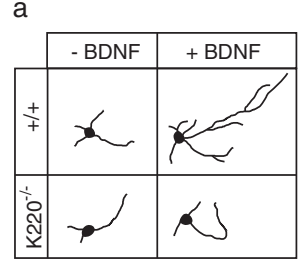

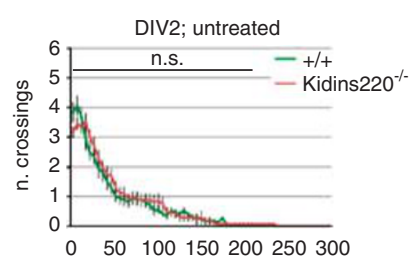

$\mu \mathrm{m}$

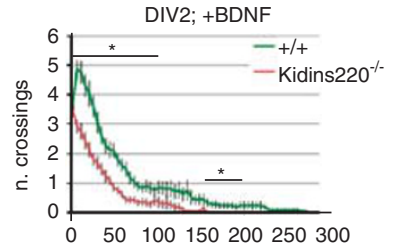

$\mu \mathrm{m}$
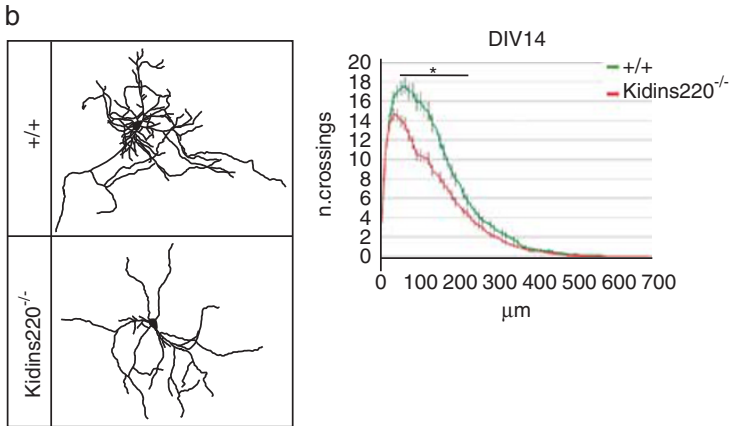

$\mu \mathrm{m}$
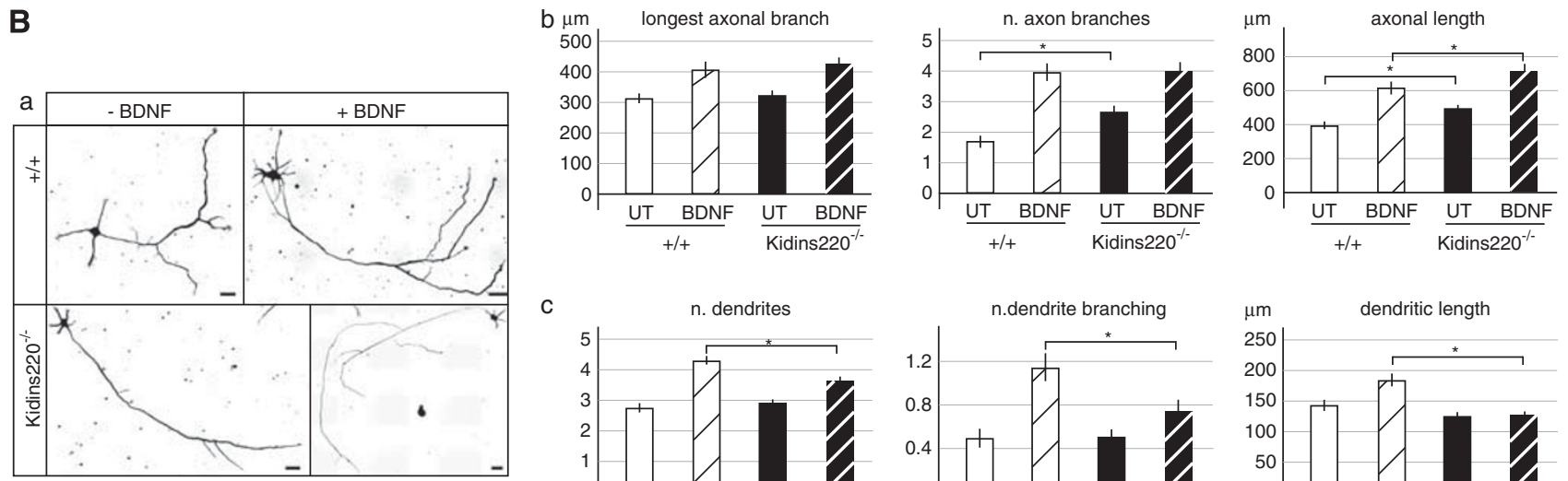

C
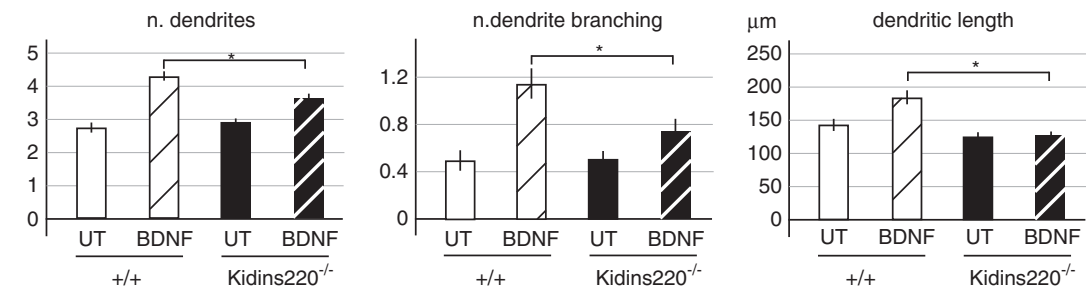

Figure 6 Altered BDNF response in Kidins220 ${ }^{-1-}$ hippocampal neurons. (A) Sholl analysis was performed on Kidins220 ${ }^{-1-}$ and wild-type hippocampal neurons at early (DIV2) and late (DIV14) stages in vitro. (a) Neurons were incubated in presence or absence of $50 \mathrm{ng} / \mathrm{ml}$ BDNF. Although basal growth was unaffected (upper graph), Kidins220 $20^{-1-}$ neurons failed to respond to BDNF (lower graph). (b) Kidins220 $0^{-/-}$neurons display a reduced ability to differentiate in response to endogenous stimuli. Representative images of each experimental condition are shown on the left. Between 15 and 21 cells (DIV2) and 70 cells (DIV14) were analyzed for each experimental condition or genotype. The number of crossings (means \pm S.E.M.) is plotted as function of the distance from the cell body $\left({ }^{*} P<0.05\right.$, Student's unpaired $t$-test). (B) Neurons were incubated for 3 days in the presence or absence of BDNF $(50 \mathrm{ng} / \mathrm{ml})$, fixed and stained with anti-SMI-31 and anti-blll-tubulin antibodies. Kidins220 ${ }^{-/-}$neurons display more branched axons under basal conditions, and increased total axonal length both under basal conditions and upon BDNF treatment, compared with wild-type cells (b). However, they show impaired dendrite network differentiation in response to BDNF (c). Representative images are shown in a (scale bars, $20 \mu \mathrm{m}$ ), quantitative analysis is provided in $b$ and c. Data are expressed as means \pm S.E.M. ( $n=100-150$ cells per condition, three independent experiments). Statistical analysis was performed by two-way ANOVA, followed by Bonferroni post-hoc test $\left({ }^{*} P<0.05\right)$

in 7 neurons the amplitude did not differ significantly from control values (Figure 8E). This effect was dependent on TrkB activation, as it was abolished by pre-treatment with $\mathrm{K} 252 \mathrm{a}$ (not shown). The absence of BDNF-evoked EPSC potentiation in a sub-population of cells has been reported previously, ${ }^{30}$ but no correlation between the initial current amplitude and the corresponding BDNF response was observed in our system. Interestingly, the vast majority of Kidins $220^{-/-}$neurons (11 out of 14 cells; $78.6 \%$ ) did not respond to BDNF and only three cells $(21.4 \%)$ displayed an increase in EPSC amplitude between 13 and $65 \%$ (Figure 8E).

\section{Discussion}

In this work and in the accompanying paper, ${ }^{1}$ we describe the generation and functional characterization of mice lacking
Kidins220, a scaffold for Trk and p75 ${ }^{\mathrm{NTR}}$ receptors. Kidins $220^{-1-}$ embryos survive until late stages of gestation but they do not survive birth. This is surprising, as another Kidins $220^{-1-}$ mouse line recently described ${ }^{23}$ displayed very early embryonic lethality, thus precluding any analysis on full knockout animals. In addition, heterozygous mice expressed reduced amount of Kidins220, a finding that was not confirmed in our mutant strain. ${ }^{1}$ Although the targeting strategy was very similar to that used here, differences in the cloning such as the precise position of the loxP sites, the embryonic stem (ES) cell strain used for the genetic recombination, or the promoter driving Cre expression might affect the overall viability of the mutant embryos.

Kidins220 in brain development. Kidins $220^{-1-}$ brains display reduced mass and enlarged ventricles. This could be due to: (i) defective neuronal differentiation, (ii) cell loss, 
and/or (iii) impaired neuronal proliferation. (i) Kidins $220^{-1-}$ neurons showed impaired BDNF-induced dendritic growth in vitro, in agreement with the role of Kidins 220 in the control of neuronal polarity and development, ${ }^{22}$ and NT-dependent cytoskeletal remodeling. ${ }^{16}$ (ii) The cell death observed in the mutant brains is more widespread than that of mice lacking

A

a
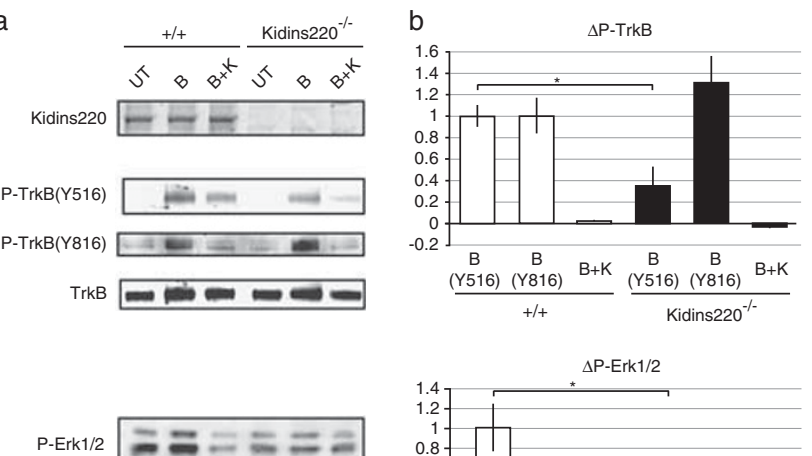

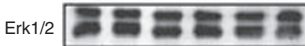
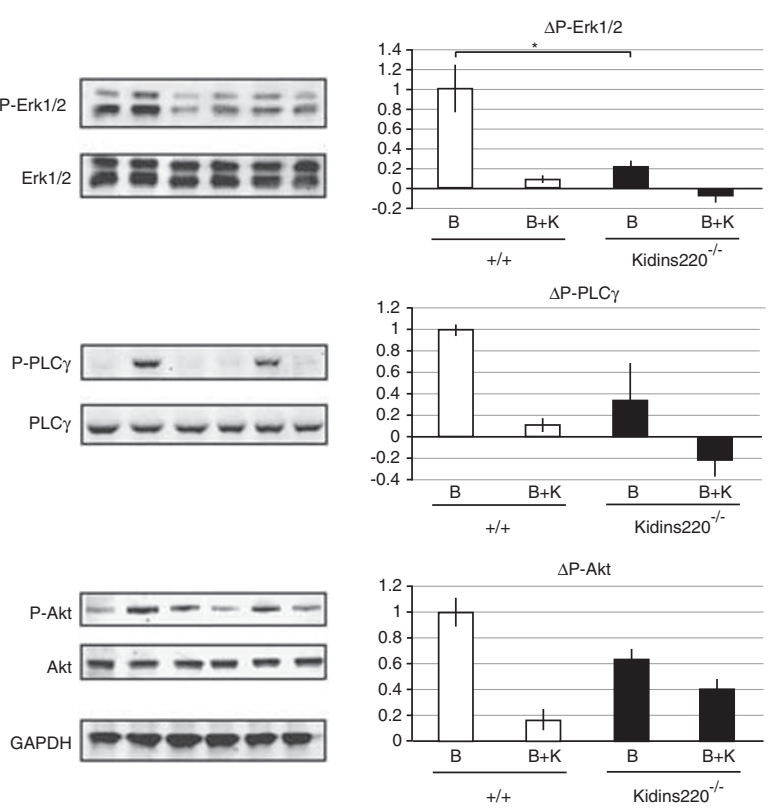

B

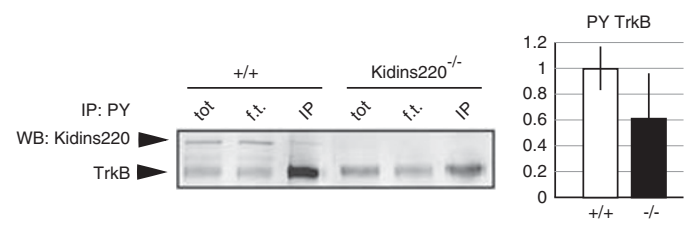

C
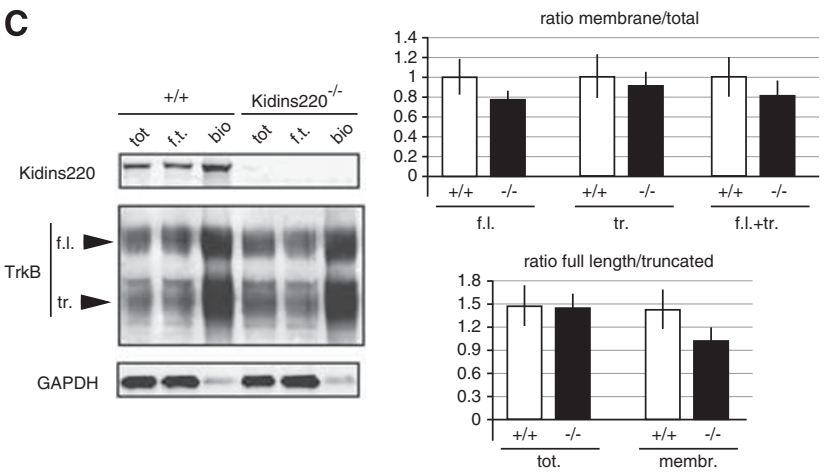

single NT or Trk receptors. ${ }^{5,8}$ This severe phenotype could be due to multiple, non-exclusive mechanisms. First, Kidins220 can potentially modulate signaling originated by all Trk receptors, thus generating a stronger phenotype than that of animals lacking only one Trk. Kidins220 deletion might uncouple Trk receptors from their physiological signaling pathways, shifting the balance toward signals mediated by p $75^{\text {NTR }}$ as recently suggested for TrkA and TrkC. ${ }^{31}$ Second, defective vascularization of the brain could lead to cell death in the subventricular zone, a finding supported by the reduced cell death observed in animals, in which Kidins220 was only ablated in neurons. ${ }^{1}$ Finally, increased susceptibility to apoptotic stimuli ${ }^{17,20}$ and a possible impairment of glial function could contribute further to the death phenotype. (iii) The cell proliferation defects we observed in knockout embryos were minor, only involving a small population of progenitors, therefore suggesting that Kidins220 acts mainly as a modulator of survival and differentiation of post-mitotic neurons.

Kidins220 in cardiovascular development. Kidins $220^{-/-}$ mice display a severe vascular phenotype, however, this does not bear similarities with that shown by NT/Trk ${ }^{12}$ or ephrin/Eph knockout animals. ${ }^{32}$ Instead, the glomeruloid structures observed in Kidins $220^{-1-} \mathrm{E} 16.5$ brains are very similar to that of $\mathrm{Nrp}^{-1-}$ mice, in which similar tufts are seen in the brain. ${ }^{27}$ Analysis of Kidins $220^{-1-}$ embryos, however, did not reveal other Nrp1-related phenotypes. We could not

Figure 7 Impaired TrkB-dependent Erk1/2 activation in Kidins220-/- neurons. (A) Cortical neurons (DIV14) from wild-type and Kidins220 ${ }^{-1-}$ embryos were treated with $50 \mathrm{ng} / \mathrm{ml} \mathrm{BDNF}$ ('B') for $40 \mathrm{~min}$, or left untreated ('UT'). Alternatively, they were pre-incubated for 30 min with the Trk-specific inhibitor K252a (200 nM) before neurotrophin addition (' $\mathrm{B}+\mathrm{K}$ '). Lysates were analyzed for phosphorylated TrkB (Tyr516 and Tyr816), PLC $\gamma$ (Tyr783), Akt (Ser473) and Erk1/2 (Thr202/ Tyr204). Membranes were subsequently stripped and re-probed for the total amount of the same proteins. GAPDH antibodies were used as loading control. Representative immunoblots are shown in a, and the corresponding analysis in b. The intensity of phosphorylated bands was first normalized to the total amount of proteins, and subsequently to the untreated samples (see Materials and Methods for details). Values are expressed as means \pm S.E.M. $\left({ }^{\star} P<0.05\right.$, Student's unpaired $t$-test, $n=3-4$ wild-type and Kidins220 $0^{-1}$ independent cultures). (B) Cortical neurons (DIV14) from wild-type and Kidins $220^{-1-}$ embryos were treated for $40 \mathrm{~min}$ with $50 \mathrm{ng} / \mathrm{ml}$ BDNF, immunoprecipitated with anti-phosphotyrosine antibodies and analyzed by SDS-PAGE. Membranes were probed with anti-Kidins220 and antiTrkB antibodies. Representative immunoblots are shown on the left and the quantitative analysis is on the right. A reduction in phosphorylated TrkB was observed in Kidins220 $20^{-1-}$ samples (expressed as percentage of wild-type values), which, however, did not reach statistical significance. Values are expressed as means \pm S.E.M. ( $n=3$ wild-type and Kidins220 ${ }^{-1-}$ cultures). (C) Cortical neurons (DIV14) from wild-type and Kidins220 ${ }^{-1-}$ embryos were incubated for $15 \mathrm{~min}$ with $2 \mathrm{mM}$ EZ-Link Sulfo-NHS-Biotin at $4^{\circ} \mathrm{C}$ to label membrane proteins. Biotinylated proteins were isolated with streptavidin beads and membranes were probed with anti-Kidins220, TrkB and GAPDH antibodies. Representative immunoblots are shown on the left and the quantitative analysis is on the right. No statistically significant differences between wild-type and Kidins $220^{-1-}$ samples were found either in the ratio between membrane localized and total TrkB (expressed as percentage of wild-type values), or in the ratio between full-length and truncated TrkB. Values are expressed as means \pm S.E.M. $(n=10-11$ wild-type and Kidins $220^{-1-}$ cultures). tot, $10 \mu \mathrm{g}$ of total lysate; f.t., flow through; bio, biotinylated membrane proteins; IP, immunoprecipitated material; f.l., full-length TrkB; tr., truncated TrkB 
a

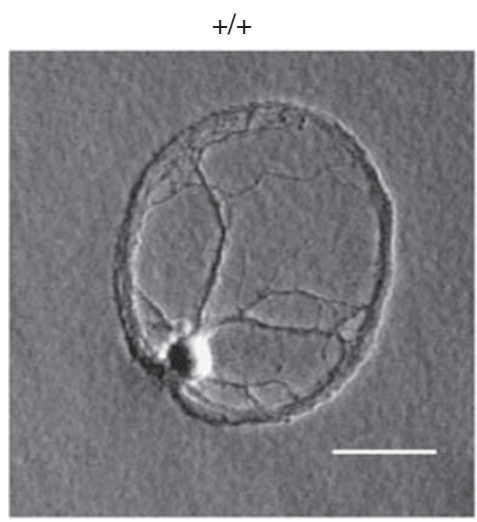

b

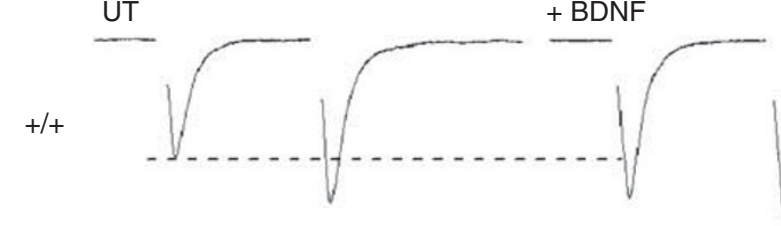

Kidins220-1-
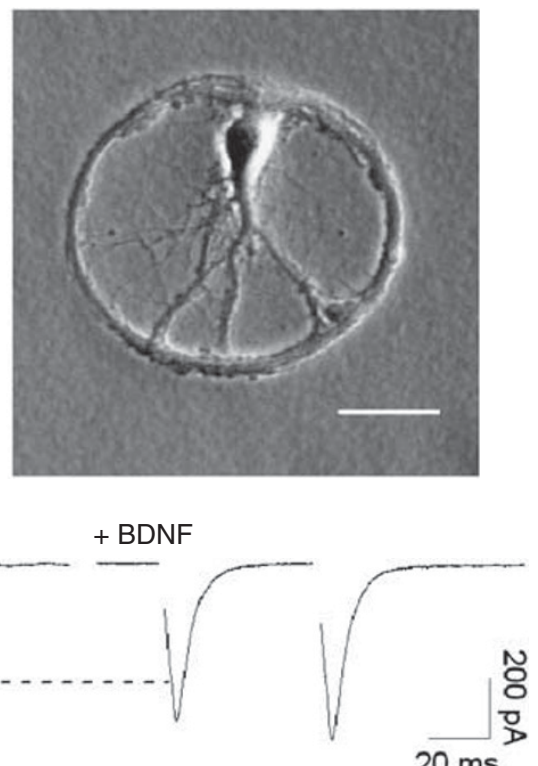

$20 \mathrm{~ms}$

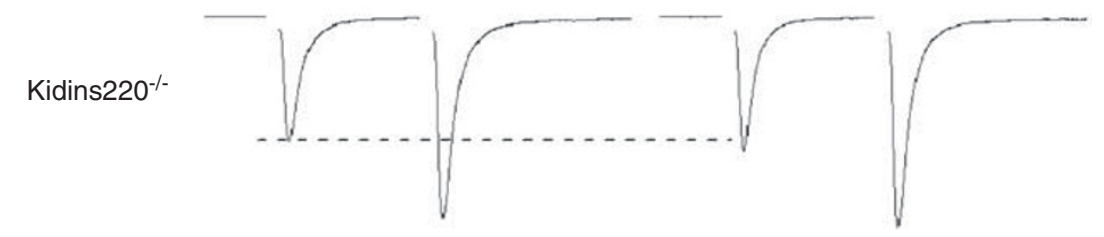

C

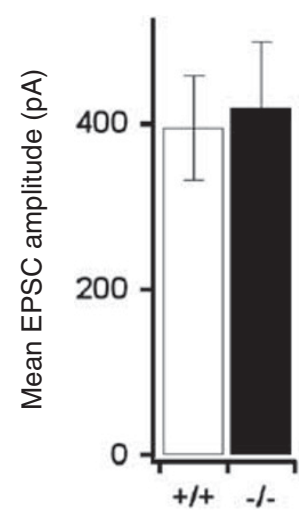

d

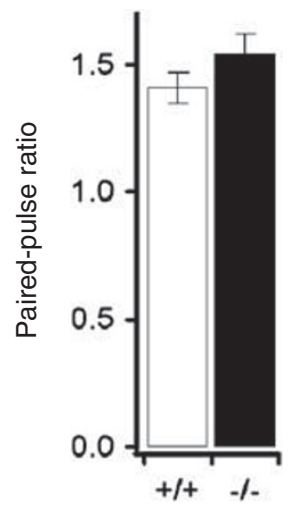

e
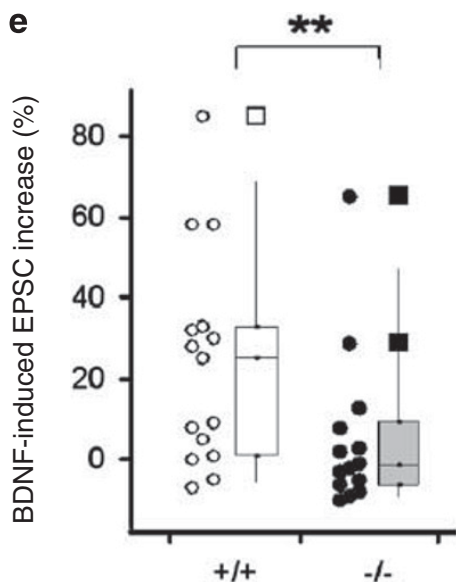

Figure 8 Electrophysiological properties of Kidins220 $0^{-1-}$ hippocampal neurons. (a) Representative autaptic hippocampal neurons from DIV13 wild-type or Kidins2220 ${ }^{-1-}$ cultures. Scale bar, $20 \mu \mathrm{m}$. (b) Paired-pulse recordings of EPSCs under control conditions (untreated, UT; left) or after addition of BDNF (100 ng/ml; right). Traces represent the average of 12 consecutive recordings. Stimulation artifacts were removed. Holding potential was set at $-86 \mathrm{mV}$. The dashed line indicates the current level in response to the first stimulus $\left(l_{1}\right)$ under control conditions. (c) Mean EPSC amplitudes $\left(l_{1} \pm\right.$ S.E.M.) recorded from wild-type $(n=45)$ and Kidins220 ${ }^{-l-}(n=30)$ autaptic neurons are comparable $\left(P>0.05\right.$; Student's unpaired $t$-test). (d) Paired-pulse ratios (PPR $=l_{2} / l_{1}$; means $\pm S$.E.M.) at an interpulse interval of 50 ms do not show significant differences between wild-type and Kidins220 $0^{-1-}$ neurons $\left(P>0.05\right.$; Student's unpaired $t$-test). Number of tested cells as in $\mathbf{c}$. (e) Increase of EPSC amplitudes $\left(I_{1}\right)$ after BDNF application $(100 \mathrm{ng} / \mathrm{ml})$ for wild-type (open circles; $n=15)$ and Kidins220 ${ }^{-l}$ neurons (closed circles; $\left.n=14\right)$. Circles represent the BDNF-induced EPSC increase for each cell analyzed. Box plots describe the positions of the median and the upper and lower quartiles. Whiskers indicate data within 1.5 times the interquartile range. Outliers are represented by square symbols. The two distributions are significantly different $\left({ }^{*} P<0.01\right.$, two-tailed Mann-Whitney U-test)

detect an interaction between Kidins220 and Nrp1, but found a constitutive binding to VEGFR2 and VEGFR3, two Nrp1 co-receptors in endothelial cells. ${ }^{33} \mathrm{VEGF}^{-1-}$, VEGFR2 ${ }^{-1-}$, $\mathrm{VEGFR3}^{-1-}$ and $\mathrm{Nrp}^{-1-}$ mice display a more severe vascular phenotype than Kidins $220^{-1-}$ and an earlier embryonic lethality. ${ }^{32,34}$ Thus, it is likely that Kidins 220 does not act as a general mediator of Nrp1/VEGFR signaling, but rather participates in specific aspects of Nrp1/VEGFR function in a tissue- and time-specific manner. Kidins $220^{-/-}$ embryos display a severe heart phenotype, ${ }^{1}$ however, further work is required to identify the function of Kidins 220 in heart morphogenesis. 
Kidins220 in PNS and MN survival. Kidins220 $0^{-1-}$ embryos display increased apoptosis in DRGs, yet no difference in the relative abundance of the most common types of sensory neurons were detected. ${ }^{1}$ Mice bearing combined Trk deletions already showed DRG loss by postnatal day 1, whereas $\mathrm{p} 75^{\mathrm{NTR}-1-}$ DRG neurons displayed unaltered NT specificity, ${ }^{2}$ similar to Kidins $220^{-1-}$ mice. This suggests that Kidins220 does not mediate a specific NT pathway in sensory ganglia, but rather acts as a general mediator of survival during early development. The increased neuronal death in vestibular and glossopharyngeal ganglia further supports a general role for Kidins220 in the mediation of trophic signals in the PNS.

$M N$ development requires the spatial and temporal coordination of several signaling pathways, with NTs providing essential cues during early stages of development. ${ }^{2}$ The small decrease in $\mathrm{MN}$ number found in Kidins $220^{-1-}$ embryos suggests that Kidins220, even though not essential for MN maintenance, might contribute to the early survival of this neuronal population.

BDNF response in Kidins220 ${ }^{-I-}$ neurons. Kidins220 $20^{-1-}$ neurons display an impaired ability to differentiate in response to BDNF and an imbalance between axonal and dendritic specification. We unveiled a specific reduction in TrkB phosphorylation at Y516, known to recruit adaptor molecules for the activation of MAPK/Erk pathway. ${ }^{2}$ Consistently, BDNF-dependent Erk phosphorylation was reduced, whereas Akt phosphorylation was unaffected, supporting previous data. ${ }^{15,20}$ Kidins 220 ablation might alter the distribution and/or dynamics of Trk and p $75^{\mathrm{NTR}}$ receptors at the membrane, or alternatively it might reduce the availability of TrkB, possibly affecting the ratio between p $75^{\mathrm{NTR}}$ homo- and heterodimers. An attractive possibility is that Kidins220 might modulate Trk recycling presynaptically, similar to that shown for NMDAR at postsynaptic level. ${ }^{18}$

BDNF influences short- and long-term synaptic plasticity both presynaptically ${ }^{30}$ and postsynaptically. ${ }^{29,35}$ EPSCs recorded from wild-type and Kidins220 ${ }^{-/-}$neurons were similar in amplitude, kinetics and paired-pulse ratio, suggesting that chronic Kidins220 ablation had no effect on AMPA-mediated transmission and short-term synaptic enhancement. Although previous studies revealed a postsynaptic role, ${ }^{17,18}$ here we propose a presynaptic role for Kidins220 in the fast adaptation of synaptic transmission to trophic stimuli.

Our data show that Kidins220 acts as a general mediator of neurotrophic signals and is involved in both the fast and longterm response to BDNF. In addition, we report a novel role for Kidins220 in brain angiogenesis via VEGFR binding. Kidins220 is the only transmembrane protein known to interact with such a diverse set of growth factor receptors. As NT, ephrin and VEGF function has been reported in CNS, PNS and cardiovascular system, an attractive prediction is that Kidins220 allows crosstalk between these pathways at the plasma membrane, modulating the amplitude or frequency of the output signals.

\section{Materials and Methods}

Materials. All biochemical reagents and drugs were from Sigma (Sigma, Milan, Italy), unless otherwise specified. Tissue culture reagents and media were from
Invitrogen (Milan, Italy) or Sigma. Restriction enzymes were from New England Biolabs (Ipswich, MA, USA) and oligonucleotides from Sigma-Genosys (London, UK). The mouse PAC (RPCI21) library, the PAC and the IMAGE clones were from MRC Geneservice (Cambridge, UK)

Antibodies. Fluorescently conjugated secondary antibodies for immunofluorescence were from Molecular Probes (Invitrogen). Fluorescently conjugated secondary antibodies for western blot analysis and immunocytochemistry were ECL Plex goat $\alpha$-rabbit IgG-Cy5 and ECL Plex goat $\alpha$-mouse IgG-Cy3 (PA45012 and PA43010, GE Healthcare, Milan, Italy), goat $\alpha$-chicken IgG-DyLight488 and donkey $\alpha$-mouse IgG-Cy3 (103-485-155 and 715-166-150, Jackson ImmunoResearch, Suffolk, UK). Monoclonal and polyclonal antibodies against Kidins220 were previously described. ${ }^{16,25}$ The following primary antibodies were used: polyclonal anti-TrkC (ab43078, Abcam, Cambridge, UK), monoclonal and polyclonal antineuronal class III $\beta$-tubulin (MMS-435P, Covance, Princeton, NJ, USA; and T2200, Sigma), polyclonal anti-active caspase 3 (AF835, R\&D Systems, Minneapolis, MN, USA), monoclonal anti-Ki-67 (M7249, Dako, Milan, Italy), monoclonal antiphosphorylated neurofilament heavy chain (SMI-310R, Covance), monoclonal anti-VEGFR3 (14-5988, eBioscience, San Diego, CA, USA), polyclonal antiVEGFR3 (AF743, R\&D Systems), monoclonal anti-HA (clone 3F10, 11867423001, Roche Diagnostic, Indianapolis, IN, USA). Polyclonal anti-TrkB (07-225), polyclonal anti-MAPK (06-182), polyclonal anti-glyceraldehyde 3-phosphate dehydrogenase (AB9132) and monoclonal anti-phosphotyrosine (clone 4G10, 05-321) were from Millipore (Billerica, MA, USA). Monoclonal anti-VEGFR2 (2479), monoclonal antiphospho-VEGFR2 (Tyr1175) (2478), monoclonal anti-Nrp1 (3725), monoclonal anti-phospho histone H3 (Ser 10) (9706S), polyclonal anti-phospho-TrkA (Tyr490)/ TrkB (Tyr516) (4619), polyclonal anti-phospho-TrkA (Tyr785)/TrkB (Tyr816) (4168), polyclonal anti-phospho Akt (Ser473) (BK4058S), polyclonal anti-Akt (9272), monoclonal anti-phosphorylated MAPK (Thr202/Tyr204) (197G2), polyclonal antiPLC $\gamma$ (2822) and anti-phospho PLC $\gamma($ Tyr783) (2821) were from Cell Signaling (Danvers, MA, USA).

Gene targeting. The mouse Kidins220 gene (mKidins220, Unigene name C330002l19Rik) maps in the region 19422500-19507200 of chromosome 12. Cloned genomic DNA corresponding to this region was isolated by screening a mouse PAC (RPCl21) library with a Kidins220-specific probe (Supplementary Table S1). Two positive clones (515-K9 and 542-124) were used for the subsequent steps. The Kidins220 cDNA was amplified from the IMAGE clone \#30543572 and inserted at the level of the unique Nrul restriction site, within exon 16 (bases 1856-1861 of mKidins220 mRNA). The $p F I r t+$ lacZ1. gck vector was previously described.$^{36}$ Male 129 ES cells were maintained following standard procedures. ${ }^{37}$ Following electroporation with $20 \mu \mathrm{g}$ of linearized vector, cells were selected in $300 \mu \mathrm{g} / \mathrm{ml}$ G418 and single-resistant colonies were expanded in duplicates in 96-well plates for freezing and genotyping. The 2F8 and 4B12 ES clones were injected into C57B/6/J blastocysts, which were then transferred into recipient $\mathrm{C} 57 \mathrm{~B} / 6 / \mathrm{J}$ females. Chimaeric males with $>70 \%$ agouti coat color were obtained from both ES lines, and mated to C57BI6/J females.

Mouse techniques. All embryos used in this study were obtained from crosses of Kidins220 $0^{+/-}$mice on the C57BL/6 background. Mice were mated overnight and separated in the morning. The development of the embryos was timed from the detection of a vaginal plug, which was considered day 0.5 . All the experiments performed on animals and embryos in the UK were under license from the UK Home Office (Animals Scientific Procedures Act 1986), approved by the Cancer Research UK Ethical Committee, whereas those performed in Italy were conducted in accordance with the European Community Council Directive dated 24 November 1986 (86/609/EEC), approved by the Italian Ministry of Health.

Northern and Southern blots. A Nhel site, situated in the $5^{\prime}$ recombination region, generated a 17-kbp band for the wild-type allele, and an 11-kbp band for the recombinant. A Sacl site in the $3^{\prime}$ region instead yielded a 4.3-kbp band for the wildtype allele, and a $6.3-\mathrm{kbp}$ band for the recombinant DNA. For Southern blot experiments, genomic DNA was extracted from the ES cells clones and digested with the appropriate enzymes (see main text and Figure 1). Digested DNA was isolated and transferred onto a Hybond $\mathrm{N}^{+}$membranes (GE Healthcare) and then hybridized with [32P]-labeled DNA probes (Supplementary Table S1), washed and exposed to an auto-radiography film (Kodak BioMax MR, Sigma). 
For northern blot experiments, the N-terminal portion of Kidins220 mRNA was identified by a probe spanning the $\mathrm{N}$-terminal cytoplasmic tail starting after the ankyrin repeats, and including the first two transmembrane domains. The $3^{\prime}$-UTR region was identified with a probe spanning about $800 \mathrm{bp}$ of the untranslated region, starting from the RNA stop codon (Supplementary Table S1). Total RNA was prepared from E18.5 brains using the RNeasy midi kit (Qiagen, Crawley, UK), separated in an agarose-formaldehyde gel and transferred onto Hybond $\mathrm{N}^{+}$ membranes. Membranes were subsequently hybridized with [32P]-labeled DNA probes in Quick Hyb hybridization buffer (Stratagene, CA, USA) overnight at $68^{\circ} \mathrm{C}$. Hybridized filters were then washed and autoradiographed.

Biochemical techniques. Cells were washed once in ice-cold PBS and lysed in RIPA buffer (50 mM Tris-HCl pH 7.4, $150 \mathrm{mM} \mathrm{NaCl}, 2 \mathrm{mM} \mathrm{EDTA,} \mathrm{NP40} \mathrm{1 \% ,}$ SDS $0.1 \%$ ) plus protease and phosphatase inhibitors (complete EDTA-free protease inhibitors, Roche Diagnostic; serine/threonine phosphatase inhibitor and tyrosine phosphatase inhibitor, Sigma) for $30 \mathrm{~min}$ at $4^{\circ} \mathrm{C}$ under constant agitation. Mouse brain tissue was extracted in the same buffer using a teflon dounce homogenizer (Wheaton, Millville, NJ, USA) and incubated as before. After centrifugation at $16000 \times g$ for $15 \mathrm{~min}$ at $4^{\circ} \mathrm{C}$, protein concentration was quantified by using Bradford Protein Assay (Bio-Rad, Hercules, CA, USA). SDS-PAGE and western blotting were performed by using precast 4-12\% NuPAGE Novex Bis-Tris Gels (Invitrogen). After incubation with primary antibodies, membranes were incubated with fluorescently conjugated secondary antibodies and revealed by a Typhoon TRIO + Variable Mode Imager (GE Healthcare). Immunoreactive bands were quantified by using the ImageQuant TL software. Intensity of phosphorylated proteins was first normalized to the total amount of corresponding protein. The percentage increase in phosphorylation was calculated according to the following ratio: (BDNF-UT)/UT, where 'BDNF' and 'UT' represent the intensity values of the bands corresponding to BDNF (or BDNF + K252a)-treated and untreated samples, respectively.

Immunoprecipitation. Following protein extraction, protein lysates were precleared using $25 \mu \mathrm{l}$ Protein A or G-Sepharose Fast Flow (SAFC, Poole, UK) for $2 \mathrm{~h}$ at room temperature. Precleared lysates were incubated $4 \mathrm{~h}$ with $5 \mu \mathrm{g}$ of VEGFR2, VEGFR3 or phosphotyrosine antibodies at $4^{\circ} \mathrm{C}$, then immunocomplexes were isolated by adding Protein A or G-Sepharose overnight at $4^{\circ} \mathrm{C}$. Purified nonimmune rabbit IgG (I 5006, Sigma) was used as a negative control.

Cell surface biotinylation. Fourteen DIV cortical neurons were incubated 30 min on ice, washed twice in ice-cold PBS and incubated for 15 min with $2 \mathrm{mM}$ EZ-Link Sulfo-NHS-Biotin (ThermoScientific, Waltham, MA, USA) in PBS. Cells were washed twice in $100 \mathrm{mM}$ glycine/PBS pH 7.4 and lysed in RIPA buffer plus protease inhibitors. Equal amounts of proteins were incubated with Streptavidin Sepharose (GE Healthcare) for $2 \mathrm{~h}$ at $4^{\circ} \mathrm{C}$. Biotinylated proteins were eluted by adding loading buffer, and boiled for $5 \mathrm{~min}$.

Immunohistochemistry. Paraffin embedding, sectioning $(4 \mu \mathrm{m})$ and hematoxylin/eosin staining were performed according to standard procedures. For immunohistochemistry, sections were microwaved in citrate buffer $(10 \mathrm{mM}$ trisodium citrate $\mathrm{pH} 6,4.5 \mathrm{mM} \mathrm{HCl}$ ) for $10 \mathrm{~min}$ for antigen retrieval. After blocking endogenous peroxidase with normal serum, sections were incubated with rabbit anti-active caspase 3 primary antibody at 1:800 for $1 \mathrm{~h}$ at RT and subsequently incubated with the appropriate biotin-conjugated goat anti-rabbit secondary antibody, tertiary $A B C$ elite reagent (Vector Laboratories, Peterborough, UK) and developed with DAB (Biogenix, Montreal, Quebec, Canada). The L4-L6 lumbar region of the spinal cord was dissected out from wild-type and Kidins220 ${ }^{-1-}$ E18.5 embryos. MNs in spinal ventral horns were identified by Niss staining on the basis of their morphology. ${ }^{26}$ Tissue sections were analyzed using a Nikon Eclipse E1000 microscope equipped with a Nikon digital camera DXM1200F, and the following Nikon Plan-Apochromat objectives: 4X 0.2 NA DIC, 10X 0.45 NA DIC, 20X 0.75 NA DIC, Nikon 40X 0.95 NA DIC (Nikon Instruments S.p.a., Firenze, Italy).

Vibratome sectioning and staining. Brains were fixed in 4\% PFA in PBS overnight at $4^{\circ} \mathrm{C}$, washed and mounted in $3.5 \%$ low-melt agarose in PBS. $200 \mu \mathrm{m}$ sections were made using a vibratome (Leica VT1000S, Milton Keynes, UK). Floating sections were blocked in $1 \%$ BSA, $0.5 \%$ Triton-100 in PBS for $2 \mathrm{~h}$ and after conditioning into Pblec (PBS pH 6.8, $1 \mathrm{mM} \mathrm{CaCl}, 1 \mathrm{mM} \mathrm{MgCl}, 0.1 \mathrm{mM} \mathrm{MnCl}_{2}$, $1 \%$ Triton X-100) were incubated with $1: 1000$ AlexaFluor-488 conjugated Isolectin B4 from Griffonia simplicifolia (121411, Invitrogen) overnight at $4^{\circ} \mathrm{C}$, washed in PBS, incubated with primary and secondary antibodies in $0.5 \%$ BSA, $0.25 \%$ Triton X-100 in PBS, and mounted in Mowiol 4-88 (Dako).
Hippocampal, cortical and bEND5 cell cultures. E18.5 hippocampi or cortices were dissected in ice-cold PBS, incubated with trypsin $0.125 \%$ for $15 \mathrm{~min}$ at $37^{\circ} \mathrm{C}$, and mechanically dissociated. Neurons were then resuspended and plated on poly-D-lysine/laminin-coated glass coverslips, in Neurobasal medium containing $10 \%$ horse serum, $2 \mathrm{mM}$ glutamine and antibiotics (plating medium). After $3 \mathrm{~h}$, the medium was removed and replaced with Neurobasal containing 2\% B27 supplement, $2 \mathrm{mM}$ glutamine and antibiotics (maintenance medium). Autaptic cultures were prepared as previously described ${ }^{38}$ bEND5 cells were cultured in DMEM (Gibco, Invitrogen) supplemented with $10 \%$ fetal calf serum (Sigma) and $2 \mathrm{mM}$ glutamine. The cells were stimulated using recombinant murine VEGF ${ }_{165}$ (450-32, Peprotech, London, UK), which is the most abundant isoform of VEGF-A.

Slice preparation. Coronal cortico-hippocampal slices (300 $\mu \mathrm{m}$ thickness) were cut from E18.5 embryonic brains using a vibratome (Microm HV650, CU65, ThermoScientific). Slices were cut at $4^{\circ} \mathrm{C}$ in a solution containing: $87 \mathrm{mM} \mathrm{NaCl}$, $25 \mathrm{mM} \mathrm{NaHCO}_{3}, 2.5 \mathrm{mM} \mathrm{KCl}, 1.25 \mathrm{mM} \mathrm{NaH}_{2} \mathrm{PO}_{4}, 0.5 \mathrm{mM} \mathrm{CaCl}_{2}, 7 \mathrm{mM} \mathrm{MgCl}$, $25 \mathrm{mM}$ glucose and $75 \mathrm{mM}$ sucrose. Slices were left to recover for $30 \mathrm{~min}$ at $\mathrm{RT}$ in $125 \mathrm{mM} \mathrm{NaCl}, 25 \mathrm{mM} \mathrm{NaHCO}_{3}, 25 \mathrm{mM}$ glucose, $2.5 \mathrm{mM} \mathrm{KCl}, 1.25 \mathrm{mM} \mathrm{NaH}_{2} \mathrm{PO}_{4}$, $2 \mathrm{mM} \mathrm{CaCl}_{2}$ and $1 \mathrm{mM} \mathrm{MgCl}_{2}$. Slices were permanently bubbled with carbogen $\left(95 \% \mathrm{O}_{2} / 5 \% \mathrm{CO}_{2}\right)$.

Immunofluorescence. Cells were fixed with 4\% PFA, 20\% sucrose in PBS for $15 \mathrm{~min}$ at RT and permeabilized with $0.1 \%$. Triton $\mathrm{X}-100$ in PBS for 5 min at RT. Samples were blocked for $30 \mathrm{~min}$ in IF buffer ( $2 \%$ BSA, $10 \%$ goat serum in PBS). Primary and secondary antibodies were diluted in IF buffer and incubated for $45 \mathrm{~min}$ at RT. In selected experiments, Hoechst (33342, $2.5 \mathrm{mg} / \mathrm{ml}$, Sigma) was added together with the secondary antibodies. Coverslips were mounted in Mowiol 4-88.

Morphological analysis of hippocampal neurons. For the analysis of axonal/dendritic growth and branching, neurons were treated for 3 days in presence or absence of $50 \mathrm{ng} / \mathrm{ml} \mathrm{BDNF}$, fixed and stained with anti-SMI-31 and anti- $\beta$-III tubulin antibodies, to identify axons and neurites, respectively. For the Sholl analysis, neurons were electroporated with a plasmid encoding GFP by using the Amaxa Mouse Neuron Nucleofector Kit (Lonza, Basel, Switzerland), and treated for 2 days with $50 \mathrm{ng} / \mathrm{ml} \mathrm{BDNF}$. Alternatively, DIV14 neurons were transfected using lipofectamine 2000 (Invitrogen) and fixed the following morning. Neurons were imaged using a BD Pathway 855 High Content Imager system equipped with a $\mathrm{UApo} / 340 \times 20 \mathrm{X} / 0.75$ air objective. Axon and dendrites were manually measured and analyzed using the NeuronJ plugin of the ImageJ software. Sholl analysis was performed by using the Sholl plugin of ImageJ (starting radius $10 \mu \mathrm{m}$, radius step size $10 \mu \mathrm{m}$, ending radius $700 \mu \mathrm{m}$ ).

DRG analysis. Lumbar and thoracic DRGs from each embryo were analyzed separately. Percentage of caspase 3-positive cells within a DRG section were calculated by dividing the number of caspase 3-positive cells per DRG section by the total cell number within a thoracic or lumbar E13.5 DRG section. Total cell number was calculated by counting two areas of $50 \times 50 \mu \mathrm{m}^{2}$ per DRG section. To analyze the data, a linear mixed effects model was used, using the 'Ime' function from the R package ' $n \mid m e^{,}$. $^{39,40}$ This allowed correct modeling of the correlation between neighboring sections within a side (left/right DRG) within a sample. There were found to be no trends in number of caspase 3-positive cells or in the total number of cells across section within a sample, so we modeled the expected percent value of caspase 3-positive cells as being constant within each sample. Using genotype as the fixed effects in $2 \times 2$ ANOVA, along with the random effects of sides within a sample and sections within a side, expected values and their standard errors for each experimental group were estimated, and hence $P$-values were calculated.

Electrophysiological recordings. Patch-clamp recordings on autaptic neurons (DIV10-15) were performed in the whole-cell configuration using an EPC10 patch-clamp amplifier (HEKA Elektronik, Lambrecht, Germany). Patch pipettes were fabricated from borosilicate glass capillaries (Kimble Chase, Vineland, NJ, USA) with a Narishige PC-10 puller. The pipette solution contained $126 \mathrm{mM}$ K-gluconate, $4 \mathrm{mM} \mathrm{NaCl}, 1 \mathrm{mM} \mathrm{MgSO}_{4}, 0.02 \mathrm{mM} \mathrm{CaCl}_{2}, 0.1 \mathrm{mM}$ 1,2-bis(2aminophenoxy)ethane- $N, N, N^{\prime} N$-tetraacetic acid, $3 \mathrm{mM} \mathrm{Na} \mathrm{N}_{2} \mathrm{ATP}, 0.1 \mathrm{mM}$ NaGTP, $15 \mathrm{mM}$ glucose, $5 \mathrm{mM}$ HEPES-KOH pH 7.30. The bath solution contained $140 \mathrm{mM}$ $\mathrm{NaCl}, 4 \mathrm{mM} \mathrm{KCl}, 2 \mathrm{mM} \mathrm{CaCl}_{2}, 1 \mathrm{mM} \mathrm{MgCl}$, $10 \mathrm{mM}$ glucose, $10 \mathrm{mM}$ HEPES-NaOH pH 7.30. D(-)2-Amino-5-phosphonopentanoic acid (50 $\mu \mathrm{M})$ and CGP $55845(5 \mu \mathrm{M}$; both from Tocris, Bristol, UK) were added to block NMDA receptors and $G A B A_{B}$ 
receptors, respectively. BDNF (Alomone, Jerusalem, Israel) was added to the bath solution at a final concentration of $100 \mathrm{ng} / \mathrm{ml}$. Experiments were performed at RT. Data acquisition and analysis were done using PatchMaster and FitMaster programs (HEKA Elektronik), respectively.

Electrophysiological data analysis. Data were acquired at $10 \mathrm{kHz}$ sample frequency and low-pass filtered at $3 \mathrm{kHz}$. EPSCs were evoked by brief depolarization. At a holding potential of $-86 \mathrm{mV}$ (off-line-corrected for liquid junction potential), a paired-pulse protocol consisting of two depolarization pulses $(0.5 \mathrm{~ms}$ $+24 \mathrm{mV}$ ) separated by a time interval of $50 \mathrm{~ms}$ was applied at $0.1 \mathrm{~Hz}$. The response to the first stimulus $\left(I_{1}\right)$ was used to determine the EPSC amplitudes under control conditions and after application of BDNF. The response to the second stimulus $\left(I_{2}\right)$ allowed for the calculation of the paired-pulse ratio PPR $=I_{2} / l_{1}$. Afte BDNF addition, EPSCs were recorded for at least $15 \mathrm{~min}$. Amplitudes were normalized to the mean value under control conditions (baseline). Average EPSC values for all temporal windows of $120 \mathrm{~s}$ (shifted from data point to data point at intervals of $10 \mathrm{~s}$ ) were determined. The effect of BDNF was evaluated by comparing the maximum value of all averages after BDNF application to the baseline value by an unpaired $t$-test. Experiments with a significantly higher mean EPSC value $(P<0.05)$ were classified as positive responses, whereas those without a significant change were taken as null responses.

Microtomography. E18.5 brains were dissected and fixed in 4\% PFA/2.5\% glutaraldehyde in $0.1 \mathrm{M}$ phosphate buffer for $1 \mathrm{~h}$, dehydrated stepwise through ethanol to $100 \%$ before critical point drying from $100 \%$ acetone. X-ray microtomography was performed on isolated brains using a SkyScan 1172 microCT system (SkyScan, Kontich, Belgium) set at $40 \mathrm{kV}$ and $250 \mu \mathrm{A}$, at a resolution of either $3.4 \mu \mathrm{m}$ (wild type) or $2.9 \mu \mathrm{m}$ (Kidins220 ${ }^{-1}$ ). The volume was reconstructed using the SkyScan NRecon program and analyzed using SkyScan CTAn software. Volume rendering was performed using Disectsoftware (Disect Systems Limited, Ipswich, UK) and videos created using Quicktime Pro.

\section{Conflict of Interest}

The authors declare no conflict of interest.

Acknowledgements. We thank $J$ Storm-Mathisen for help with the anatomical analysis, F Succol and M Nanni for technical assistance with primary neuronal cultures, $C$ Ruhrberg for help with the analysis of $\mathrm{Nrp1}^{-1-}$-like phenotypes, G Kelly for statistical analysis, A Weston and T Arnett for microCT, $\mathrm{N}$ Corps for the CTAn software and scanning, CL Thomas for critical reading of the manuscript and members of the Molecular Neuropathobiology laboratory for helpful discussion. This study was supported by research grants from: Cancer Research UK (FC, AY, BS-D and GS); the Italian Institute of Technology (FC, JS-S, PB and FB); the Italian Ministry of University and Research (FB and PB); the Italian Ministry of Health Progetto Giovani (PB); the Compagnia di San Paolo, Torino (FB, PB); Telethon-Italy (Grant GGP09134 to FB and GGP09066 to PB); BBSRC (MAQ and MK)

1. Huang EJ, Reichardt LF. Neurotrophins: roles in neuronal development and function. Annu Rev Neurosci 2001; 24: 677-736.

2. Paratcha G, Ledda F. GDNF and GFRalpha: a versatile molecular complex for developing neurons. Trends Neurosci 2008; 31: 384-391.

3. Lu B, Pang PT, Woo NH. The yin and yang of neurotrophin action. Nat Rev Neurosci 2005; 6: 603-614.

4. Snider WD. Functions of the neurotrophins during nervous system development: what the knockouts are teaching us. Cell 1994; 77: 627-638.

5. Klein R, Smeyne RJ, Wurst W, Long LK, Auerbach BA, Joyner AL et al. Targeted disruption of the trkB neurotrophin receptor gene results in nervous system lesions and neonatal death. Cell 1993; 75: 113-122.

6. Alcantara S, Frisen J, del Rio JA, Soriano E, Barbacid M, Silos-Santiago I. TrkB signaling is required for postnatal survival of CNS neurons and protects hippocampal and motor neurons from axotomy-induced cell death. J Neurosci 1997; 17 3623-3633.

7. Bibel M, Barde YA. Neurotrophins: key regulators of cell fate and cell shape in the vertebrate nervous system. Genes Dev 2000; 14: 2919-2937.

8. Ernfors $P$, Van De Water T, Loring J, Jaenisch R. Complementary roles of BDNF and NT-3 in vestibular and auditory development. Neuron 1995; 14: 1153-1164.
9. Schimmang T, Minichiello L, Vazquez E, San Jose I, Giraldez F, Klein R et al. Developing inner ear sensory neurons require TrkB and TrkC receptors for innervation of their peripheral targets. Development 1995; 121: 3381-3391.

10. Crowley C, Spencer SD, Nishimura MC, Chen KS, Pitts-Meek S, Armanini MP et al. Mice lacking nerve growth factor display perinatal loss of sensory and sympathetic neurons yet develop basal forebrain cholinergic neurons. Cell 1994; 76: 1001-1011.

11. Caporali A, Emanueli C. Cardiovascular actions of neurotrophins. Physiol Rev 2009; 89 : 279-308.

12. Iglesias T, Cabrera-Poch N, Mitchell MP, Naven TJ, Rozengurt E, Schiavo G. Identification and cloning of Kidins220, a novel neuronal substrate of protein kinase D. J Biol Chem 2000; 275: 40048-40056.

13. Kong $\mathrm{H}$, Boulter J, Weber JL, Lai $\mathrm{C}$, Chao MV. An evolutionarily conserved transmembrane protein that is a novel downstream target of neurotrophin and ephrin receptors. $J$ Neurosci 2001; 21: 176-185.

14. Arevalo JC, Yano H, Teng KK, Chao MV. A unique pathway for sustained neurotrophin signaling through an ankyrin-rich membrane-spanning protein. EMBO J 2004; 23: 2358-2368.

15. Neubrand VE, Thomas C, Schmidt S, Debant A, Schiavo G. Kidins220/ARMS regulates Rac1-dependent neurite outgrowth by direct interaction with the RhoGEF Trio. J Cell Sci 2010; 123: 2111-2123.

16. Lopez-Menendez C, Gascon S, Sobrado M, Vidaurre OG, Higuero AM, Rodriguez-Pena A et al. Kidins220/ARMS downregulation by excitotoxic activation of NMDARs reveals its involvement in neuronal survival and death pathways. J Cell Sci 2009; 122: 3554-3565

17. Arevalo JC, Wu SH, Takahashi T, Zhang H, Yu T, Yano $\mathrm{H}$ et al. The ARMS/ Kidins220 scaffold protein modulates synaptic transmission. Mol Cell Neurosci 2010; 45 : $92-100$.

18. Luo S, Chen Y, Lai KO, Arevalo JC, Froehner SC, Adams ME et al. \\{alphal\}-Syntrophin regulates ARMS localization at the neuromuscular junction and enhances EphA4 signaling in an ARMS-dependent manner. J Cell Biol 2005; 169: 813-824.

19. Sniderhan LF, Stout A, Lu Y, Chao MV, Maggirwar SB. Ankyrin-rich membrane spanning protein plays a critical role in nuclear factor-kappa B signaling. Mol Cell Neurosci 2008; 38: 404-416.

20. Cortes RY, Arevalo JC, Magby JP, Chao MV, Plummer MR. Developmental and activitydependent regulation of ARMS/Kidins220 in cultured rat hippocampal neurons. Dev Neurobiol 2007; 67: 1687-1698.

21. Higuero AM, Sanchez-Ruiloba L, Doglio LE, Portillo F, Abad-Rodriguez J, Dotti CG et al. Kidins220/ARMS modulates the activity of microtubule-regulating proteins and controls neuronal polarity and development. J Biol Chem 2010; 285: 1343-1357.

22. Wu SH, Arevalo JC, Sarti F, Tessarollo L, Gan WB, Chao MV. Ankyrin repeat-rich membrane spanning/Kidins220 protein regulates dendritic branching and spine stability in vivo. Dev Neurobiol 2009; 69: 547-557.

23. Cesca F, Yabe A, Spencer-Dene B, Arrigoni A, Al-Qatari M, Henderson D et al. Kidins220/ ARMS is an essential modulator of cardiovascular and nervous system development. Cell Death Dis 2011; e-pub ahead of print 3 November 2011, doi:10.1038/cddis.2011.108.

24. Lallemand $Y$, Luria $V$, Haffner-Krausz $R$, Lonai $P$. Maternally expressed PGK-Cre transgene as a tool for early and uniform activation of the Cre site-specific recombinase. Transgenic Res 1998; 7: 105-112.

25. Bracale A, Cesca F, Neubrand VE, Newsome TP, Way M, Schiavo G. Kidins220/ARMS is transported by a kinesin-1-based mechanism likely to be involved in neuronal differentiation. Mol Biol Cell 2007; 18: 142-152.

26. Bilsland LG, Dick JR, Pryce G, Petrosino S, Di Marzo V, Baker D et al. Increasing cannabinoid levels by pharmacological and genetic manipulation delay disease progression in SOD1 mice. FASEB J 2006; 20: 1003-1005.

27. Gu C, Rodriguez ER, Reimert DV, Shu T, Fritzsch B, Richards LJ et al. Neuropilin-1 conveys semaphorin and VEGF signaling during neural and cardiovascular development. Dev Cell 2003; 5: 45-57.

28. Olsson AK, Dimberg A, Kreuger J, Claesson-Welsh L. VEGF receptor signalling - in control of vascular function. Nat Rev Mol Cell Biol 2006; 7: 359-371.

29. Levine ES, Dreyfus CF, Black IB, Plummer MR. Brain-derived neurotrophic factor rapidly enhances synaptic transmission in hippocampal neurons via postsynaptic tyrosine kinase receptors. Proc Natl Acad Sci USA 1995; 92: 8074-8077.

30. Li YX, Zhang Y, Lester HA, Schuman EM, Davidson N. Enhancement of neurotransmitter release induced by brain-derived neurotrophic factor in cultured hippocampal neurons. J Neurosci 1998; 18: 10231-10240.

31. Sharma N, Deppmann CD, Harrington AW, St Hillaire C, Chen ZY, Lee FS et al. Long-distance control of synapse assembly by target-derived NGF. Neuron 2010; 67: $422-434$

32. Gale NW, Yancopoulos GD. Growth factors acting via endothelial cell-specific receptor tyrosine kinases: VEGFs, angiopoietins, and ephrins in vascular development. Genes Dev 1999; 13: 1055-1066

33. Soker S, Takashima S, Miao HQ, Neufeld G, Klagsbrun M. Neuropilin-1 is expressed by endothelial and tumor cells as an isoform-specific receptor for vascular endothelial growth factor. Cell 1998; 92: 735-745.

34. Kitsukawa T, Shimizu M, Sanbo M, Hirata T, Taniguchi M, Bekku $Y$ et al. Neuropilinsemaphorin III/D-mediated chemorepulsive signals play a crucial role in peripheral nerve projection in mice. Neuron 1997; 19: 995-1005. 
35. Kovalchuk Y, Hanse E, Kafitz KW, Konnerth A. Postsynaptic induction of BDNF-mediated long-term potentiation. Science 2002; 295: 1729-1734.

36. Compagni A, Logan M, Klein R, Adams RH. Control of skeletal patterning by ephrinB1EphB interactions. Dev Cell 2003; 5: 217-230.

37. Robinson EJ. Teratocarcinomas and Embryonic Stem Cells: A Practical Approach (Practical Approach Series). Oxford University Press: USA, 1987.
38. Bekkers JM, Stevens CF. Excitatory and inhibitory autaptic currents in isolated hippocampal neurons maintained in cell culture. Proc Natl Acad Sci USA 1991; 88: 7834-7838.

39. Pinheiro JC, Bates DM. Mixed Effects Models in S and S-Plus. Springer, 2002.

40. Team RDC. R: A language and environment for statistical computing ISBN 3-900051-07-0 2010.

Supplementary Information accompanies the paper on Cell Death and Differentiation website (http://www.nature.com/cdd) 